\title{
Impact of Regulations on Hedge Funds and the Potential Impact on Alpha in 2012
}

\section{Payal Chadha*}

Swiss Management Center University Zug, Kuwait

\begin{abstract}
Growth in the hedge fund industry has been a topic of much discussion in the press with regards to regulators regulating the hedge fund industry. The purpose of this study was to investigate whether creating regulations, has impacted the hedge fund industry and alpha components. The focus has mainly been aimed at the hedge fund industry existing in USA and Europe. Minor contrasts have been made in comparison with Canada and Latin America. The author has defined hedge funds, its salient features, its functioning, different strategies used, reason for introducing regulations, challenges faced and the developments that are occurring and have occurred in the industry for smooth operation. The author also defines alpha and its nature in the hedge fund industry in order to understand if any impact has been made due to these regulatory approaches. The author discusses the current and upcoming hedge fund regulations in 2012. The exploratory method was used to conduct the study further. This method involves usage of both qualitative and quantitative data. Finally, the author uses both primary and secondary data to derive conclusions based on the understanding and knowledge gained through the literary sources.
\end{abstract}

Keywords: Market risk; Investment strategies; Financial markets; Capital markets

\section{Introduction}

\section{Background}

The concept of hedge fund came into existence in 1949 by Alfred Winslow Jones as he hedged his long stock positions by selling short other stocks to protect against market risk. Although his work was recognized by the public in 1966, it was much later in 1984 that research on hedging industry began with Sandra Manske, who also formed Tremont Partners [1].

A hedge fund is defined as "an aggressively managed portfolio of investments that uses advanced investment strategies with the goal of generating high returns" [2]. They are often domiciled offshore, for tax and regulatory reasons. And, unlike traditional funds, they are not burdened by regulation [3].

"To "hedge" is to lower overall risk of taking on an asset position that offsets an existing source of risk. For example, an investor holding a large position in foreign equities can hedge the portfolio's currency risk by going short currency futures. A trader with a large inventory position in an individual stock can hedge the market component of the stock's risk by going short equity index futures" [4].

Hedge funds play a valuable arbitrage role in reducing or eliminating mispricing in financial markets. They are an important source of liquidity, both in periods of calm and stress. They add depth and breadth to our capital markets [5].

Hedge funds are composed of three important components: legal structure, investment strategy and investor pool. Some of its salient features are as follows:

I. Hedge funds are legally limited partnerships.

II. They are unregistered investment companies that are not regulated by the Securities and Exchange Commission (SEC).

III. They are users of a variety of investment strategies and products, including options, future, swaps and short selling.
IV. Often employ leverage, in that the amount of notional market exposure often exceeds the investment capital of the fund.

V. Has limited liquidity that is investors can only get into funds on certain dates and can only get their money out of funds on certain dates (Also known as liquidity dates) [6].

Typically, wealthy individuals must be deemed by SEC as an accredited investor in order to invest in hedge funds (Defined by SEC rule 501 of Regulation $\mathrm{D}$ ). This rule includes the following points:

i. The individual must have at the time of investment a net worth (or joint net worth with a spouse) exceeding $\$ 1,000,000$, or;

ii. The individual must have an individual income exceeding $\$ 200,000$ in each of the two most recent years or joint income with a spouse exceeding $\$ 300,000$ in each of the two most recent years, and must have a "reasonable expectation" of reaching the same level in the coming year in order to invest in an unregistered investment company.

iii. The organization must have total assets in excess of $\$ 5,000,000$, or;

iv. The organization's owners must be accredited investors [6].

Investments can also be made through endowments for example, the Wall Street Journal; and pension funds for example, Pension and Investments magazine regularly reports of pension fund activity investing in new hedge funds [6].

Hedge funds have a fee structure comprising of both fixed fee and management fee. The fixed fee usually ranges from 1 and $2 \%$ of

${ }^{*}$ Corresponding author: Chadha P, Swiss Management Center, University Zug, Kuwait, Tel: +96569078096; E-mail: payal.chad@gmail.com

Received May 12, 2016; Accepted July 30, 2016; Published August 05, 2016

Citation: Chadha P (2016) Impact of Regulations on Hedge Funds and the Potential Impact on Alpha in 2012. Int J Account Res S1: 009. doi: 10.4172/2472114X.S1-009

Copyright: (C) 2016 Chadha P. This is an open-access article distributed under the terms of the Creative Commons Attribution License, which permits unrestricted use, distribution, and reproduction in any medium, provided the original author and source are credited. 
assets under management and the management fee ranges from 20 and $25 \%$ of upside performance. As hedge funds are unregulated, these ranges are often exceeded, and can be as high as $5 \%$ fixed fee and $25 \%$ management fee. Hedge fund fees are often quoted in a language such as " 2 and 20 " meaning $2 \%$ fixed fee and 20\% management fee [6].

The other terms that are used in context of hedge fund fee structure are:

i. Benchmark: for example Suppose at the beginning of the year 1 a hedge fund has a net asset value of 100 , and throughout the year the fund realizes a $25 \%$ return, raising the net asset value to 125 (that is the fund with a $\$ 1,000,000$ investment at the beginning of year 1 then "shares" would be worth $\$ 1,250,000$ gross of fees). If the benchmark was cash, say $5 \%$, then the fees would be paid on the $\$ 200,000$ upside in excess of cash that is the first $5 \%$ of the return would not have to have fees paid for it. If the fees were 2 and 20 , then the investor would pay $\$ 20,000$ in the fixed fee $(2 \%)$ and $20 \%$ of the upside, above cash, that is an additional $\$ 40,000$ for a total of $\$ 60,000$ in fees. This would make the investment value, gross of fees, equal to $\$ 1,190,000$.

ii. High water mark: for example suppose an investor enters a hedge fund with a $\$ 1,000,000$ at the beginning of the year 1 , and in that year the fund is down $20 \%$, that is, the value of the investment drops to $\$ 800,000$ gross of fees. The investor still pays the management fee (called fixed fee), but the investor pays no management fee. Now suppose that after the year 2 the investment value is up to $\$ 1,200,000$, representing over a $30 \%$ gain in year two for the fund. The investor, nevertheless, only pays a management fee on $\$ 200,000$, that is, he/she only pays a fee on the amount in excess of the entering NAV. The entering $\mathrm{NAV}$ in this case is called the high water mark. In subsequent years if there is a drop in NAV, the new high water mark will be the entering NAV of the previous year, or the previous high water mark, whichever is greater" [6]

Hedge funds have two forms of liquidity constraints that are imposed on investors: lockup and minimum investment [6]. The classification of hedge funds is according to the type of investment strategies used to run them. They are as follows:

i. "Market Neutral (or Relative Value) Funds: attempt to produce return series that have no or low correlation with traditional markets such as the US equity or fixed income markets. They are highly quantitative in their portfolio construction process, and market themselves as an investment that can improve the overall risk/return structure of a portfolio of investments.

ii. Event Driven Funds: seek to make profitable investments by investing in a timely manner in securities that are presently affected by particular events. Such events include distressed debt investing, merger arbitrage (sometimes called risk arbitrage) and corporate spin-offs and restructuring.

iii. Long/Short Funds: generally invest in equity and fixed income securities, taking directional bets on either an individual security, sector or country level. For example a fund might do pairs trading, and buy stocks that they think will move up and sell stocks they think will move down. Or go long sectors they think will go up and short countries they think will go down. Long/Short strategies are not automatically market neutral that is, a long/short strategy can have significant correlation with traditional markets, and surprisingly have seen large down turns in exactly the same times as major market downturns. iv. Tactical Trading: refers to strategies that speculate on the direction of market prices of currencies, commodities, equities and/or bonds. Managers typically are either systematic or discretionary. Systematic managers are primarily trend followers who rely on computer models based on technical analysis. Discretionary managers usually take a less quantitative approach and rely on both fundamental and technical analysis. This is the most volatile sector in terms of performance because many managers combine long and/or short positions with leverage to maximize returns" [6].

\section{Problem}

Historically, hedge funds have operated in the exceptions and exemptions of the Securities Act of 1933 (there is no public offering), the Securities and Exchange Act of 1934 (they are not publicly traded companies), the Investment Company Act of 1940 (they are not mutual funds), and, until recently, the Investment Advisers.

In the U.S., hedge funds have been largely an unregulated investment vehicle that has accumulated over a trillion dollars in assets by 2005 . With a trillion dollars of capital under management and with $5 \%$ alphas returns promised by maximum hedge funds, this implies that there needs to be at least an aggregate above market return of $\$ 50$ billion per annum, this apparently is not the case. Thus far, the SEC has responded to calls to regulate hedge funds with fairly mild registration requirements that took effect in February of 2006.

The financial crisis of 2008 was largely the result of excessive debt and the resulting underpricing and mispricing of risk. It is believed that directly or indirectly hedge funds contributed to this financial bubble and credit crunch. After the crisis, the big banks intensified their focus on the top 250 or so managers at the expense of the smaller hedge funds [7].

\section{Purpose}

The need for regulations is for regulatory authorities to assess the systemic risk posed and properly price this risk. The other issues that hedge funds deal with are: i) the high leverage that hedge funds use to boost their gains and ii) hedge funds don't like to disclose their positions or trading activities [8].

The key problem that has been discussed often, but not understood yet is the range of complex legal and governance issues that are challenging the industry and require immediate attention. However, it will be difficult to create a global regulatory system that every country will agree upon [9]. The SEC lists as one of its primary reasons for its new hedge fund regulations, a number of troubling incidences of fraud perpetrated by hedge fund operators [10].

"The combination of factors like large size, elite investors, big returns on high risks, speed, trading sophistication, and attacks on established interests, secrecy, and periodic, spectacular failure create an opportunity to stimulate popular fear of a new breed of shadowy financial monsters. The populist anti-hedge fund spin almost writes itself: a wealthy, backroom elite group of investors, driven by selfish greed, take excessive risks with cheater-style trading strategies that imperil the health of our banks and our corporations that is our entire economy [11]. And popular fear creates a cry for government control that is heard by politicians courting voters.

One can argue that stricter rules and regulations help a market to operate as evidenced by the performance of the South American markets in recent years that have fallen under increasingly stricter 
guidelines, that is all funds coming in as foreign investment are required to be registered with the local securities regulator and produce regular accounts of their investments. Moreover, in Canada, where the banking system is considered to be more regulated than that of the US, there were no banking collapses throughout the 2008 financial crises and beyond.

The study focuses on the regulations that have been proposed and implemented, the challenges that exist in the market when it comes to regulating hedge funds and whether alpha has improved or declined.

However, overcrowding within financial markets makes it harder for managers to stand out. Otherwise said, when hedge funds were considered a cottage industry buoyed by abundant market inefficiencies, generating large alpha returns was easy. Now, with an estimated 9,000 hedge funds, dozens or hundreds of managers may be pursuing the same strategy effectively cannibalizing each other's alpha return [12].

\section{Research question}

The purpose of the contemplated study is to examine whether increased regulation of the hedge fund industry will have significant impact on future alpha return, and whether increased regulation will help to prevent future economic crises. Therefore, the objective is:

i. To study the impact of regulations on hedge funds so far,

ii. The challenges posed by these regulations,

iii. The new policies that could be introduced to improve the industry, and

iv. The impact on alpha due to regulations.

\section{The research question:}

Keeping the above objectives in mind the study will attempt to answer the following specific question:

"What will be the impact of regulations in the hedge fund industry as evidenced by the level of expected alpha return?

In responding to the above, a series of secondary questions will be examined in order to further shed light on the issues at hand namely:

1. Is increased regulations expected to be beneficial or detrimental to the industry as evidenced by future anticipated alpha returns?

2. What challenges will be faced by the hedge fund industry in maintaining alpha returns when new regulations are introduced by the respective authorities?"

\section{Significance}

The significance of the dissertation is to update previous research and development in an attempt to generate the foundational knowledge and understanding of future of hedge funds industry worldwide.

With the above in mind, the study proposes to question the hedge fund specialists (approximately 24) about their knowledge of regulations in the industry and generation of positive alpha. The proposition is to analyze the future impact of these regulations, whether it will be positive or negative, whether it will stabilize the market overall, whether the risks will be expected to minimize the losses in the hedge fund industry.

A preliminary review of the literature suggests that the academic communities along with professional participants have provided some indication of the resultant impact of future regulation on expected alpha levels. However, this relationship still remains fairly opaque and questionable. Thus, the contemplated study will strive to shed further light on this relationship and help to bridge the gap in the existing literature with respect to this topic.

As previously mentioned, the study will analyze the sources from published academic papers, conclude interviews with a hedge fund specialists using a qualitative semi structured interview survey method via questionnaires and gathering data to generate alpha and beta. This will help predict the impact on alpha with the use of regulations and what the future direction may be.

\section{Nature of research}

The overall goal is to study the impact of regulations on hedge funds. The aim is to examine whether alpha improves or declines with regulations introduced in the industry. This dissertation aims to be instrumental in understanding the viewpoints of various hedge fund specialists around the world, the influence and effectiveness of regulations as of the current scenario and how to achieve optimal performance after the huge financial crisis of 2008.

\section{Summary}

As illustrated thus far, the study of hedge funds and regulations is still an ongoing area of research. In general, there has not been extensive research with regards to regulations in the hedge fund industry. The nature of the study is to explore the established and the upcoming regulations and its impact on alpha component. It should be noted that there still exists a great deal of uncertainty in this study. This study highlights the upcoming trends in the hedge fund industry and sheds further light on the overall performance of this industry.

The study aims to build an understanding that can be used for future frameworks to investigate current knowledge and develop new strategies/suggestions on how to avoid downfall in case of a market crash. Lastly, a supplemental aim of the dissertation is to develop a content dictionary of key terms with respect to hedge funds used.

Chapter 2 covers the Literature Review in detail, stating the ideas developed so far with respect to the regulations followed by research methods used in Chapter 3 that leads to the data gathering in Chapter 4 with results and analysis in Chapter 5 followed by in depth conclusions and recommendation in Chapter 6.

\section{Chapter Two Literature Review}

\section{Overview}

The aim of the dissertation is to understand the role regulations play in the hedge fund industry, its impact and reflection on alpha. It is grounded in the scholarly literature of the seminal writers, newspaper articles, journals and online web resources to enhance our knowledge of the hedge fund industry with the past and current events. The literature review section presents a general overview of what the literature of the domain reveals with respects to elucidating the research question. General themes covered within the seminal literature revolve around the topics of:

i. The impact of regulations on hedge funds so far,

ii. The challenges posed by these regulations,

iii. The new policies that could be introduced to improve the industry, and

iv. The impact on alpha component due to regulations. 
The literature to be used within the research originated from various academic sources, including: University of Wales online library; Monarch University UGSM Monarch Business School's Library Resources named JStor eJournal Library Access, Google search engine, research white papers from various consultancies, such as: like Oliver Wyman, McKinsey Consulting, KPMG Consulting, Price Waterhouse Coopers as well as important web based financial sources such as the Financial Times and specific hedge fund industry sites. Other sources taken into consideration would be Academic Authors like Phillip Swagel, Philip Lane, Stephen Morris, Alan Greenspan, Oliver Blanchard, Gary Gorton, Andre Lo, Rene Stulz, Franklin Edwards and Surendra Arjoon; Industry Web Site Publications like Hedgeworld. com, Finalalternatives.com, Hedgefund.net, Google News On Hedge Funds, Hedge Fund Association, Barclay's Hedge Fund Database, SEC Website on Hedge Funds, Hedgeweek.com, SeekingAlpha.com, Harvard Hedge Fund Guide at Harvard University Baker Library, NY Times Dealbook, HedgeFundResearch.com, and annual reports or specific white papers.

\section{Functioning of hedge funds}

Let's begin the discussion firstly with how hedge funds function. The strategies that hedge funds use have already been discussed above in the introduction section. "Most hedge funds attempt to find trades that are almost arbitrage opportunities-pricing mistakes in the markets that can produce low-risk profits. Once a mispriced asset is identified, hedges are devised for their position so that the fund will benefit from the correction of the mispricing but be affected by little else" [13]

"Because hedge funds seek inefficiencies in the capital markets and attempt to correct them, they can play a valuable role in financial markets by bringing security prices closer to fundamental values. With their focus on arbitrage opportunities, hedge funds in principle pursue absolute returns rather than returns in excess of a benchmark, such as an index of the stock or bond markets. Since hedge funds are not regulated, they need not disclose their performance. Databases only report the performance of hedge funds that voluntarily send their returns to the sponsoring organizations" [13].

"Hedge funds do well because hedge fund managers recognize quickly the changing market trends, and try to profit from such developing trends before other mainstream investors see such trends. Through diversification, many hedge funds limit their risk exposure levels, a strategy that serves as a defense mechanism in case of a sudden change in market trend. Other hedge fund managers apply advanced asset allocation techniques through analysis of traditional data in combination with technical analysis to decide asset allocation models which best suits their interests" [14].

\section{Discussion on alpha}

"Alpha is return over and above whatever the beta of their portfolio might be. Hedge fund managers are always on the lookout for ways to increase their alpha. One way to do that is to get high returns; another way to do that is to decrease the beta" [15]. "It is usually unstable and can't predict information on future betas and alphas. Not all hedge fund absolute returns can be considered as alpha. The fact is many alphas turn out to be negative after looking at the risks and factor exposures taken to generate that performance. But true alpha is what the $2 \%$ and $20 \%$ fees are for (as discussed in Chapter 1). Some investors choose to pay intermediary allocators an extra layer of $1 \%$ and $10 \%$ to source and locate that alpha and conduct expensive and time consuming manager due diligence. An added complication is that if its longs were high beta and shorts were low beta, the hedge fund would have needed to make an even higher absolute return for any alpha. Alpha is the return after allowing for dependence on beta risk factors" [16].

According to Wall Street Journal article titled "Hedge Funds Kiss Their Alpha Goodbye, the gap between hedge fund returns and market returns for the past five years has not been positive hurting the ability of many hedge funds to generate much alpha due to extreme correlation [17]. "For example the S\&P 500 has a beta of 1, or $100 \%$; the first hedge fund manager has a beta of 2 , or $200 \%$; and the second hedge fund manager has a beta of 5 , or $500 \%$. The riskier and more volatile the assets you're investing in, the higher their beta. And, of course, as leverage increases, beta increases proportionately [15].

\section{Recent developments}

"Increasing amounts of government intervention in worldwide financial markets has created an unprecedented correlation amongst asset classes, increased volatility and a tougher environment for skill based managers to generate superior risk adjusted returns" [18].

"Management fees remained broadly flat, but incentive or performance fees continued their downwards trajectory, due to pressure from investors and relatively poorer returns [19]. European institutions led by the U.K. are expected to raise/change their hedge fund allocations in a bid to improve funding levels while controlling portfolio volatility better, industry observers say. These allocations among pension funds in the U.K. benefit investment assets could as much as double in the next several years, sources said.

Investors are betting on positive returns and growth in hedge funds even after market selloffs followed by "quick and exaggerated snapbacks" made it difficult for many managers to consistently make money last year. In 2011 alone, the average pension fund allocation to hedge funds jumped to $4.1 \%$, or about $£ 33$ billion ( $\$ 52$ billion) from 2.6\%, according to data from the National Association of Pension Funds. Consultants such as Aon Hewitt recommends that some pension funds could make an allocation to hedge funds of $30 \%$ or more within the return-seeking portfolio, depending on the risk/ return target of the fund, said Guy Saintfiet, the U.K. head of liquid alternatives at Aon Hewitt, based in London. Furthermore, institutions are also altering hedge fund strategies to reduce correlation, illiquidity and beta exposures [20].

An impressive $80 \%$ of institutional investors either grew or maintained their hedge fund holdings in 2011 in a bullish endorsement of the hedge fund industry. Global hedge fund assets may rise 12 percent this year to a record $\$ 2.26$ trillion as investors reduce cash and seek returns, according to an annual survey of investors by Deutsche Bank AG. The industry may see $\$ 250$ billion of net inflows and performance gains this year, according to the survey. The number of investors with 10 percent to 30 percent of their holdings in cash is expected to halve in the next six months, helping free up $\$ 39$ billion for potential hedge fund investments, the survey showed [21].

Institutional investors recognize the potential for strong hedge fund returns in 2012. Deutsche Bank in December polled 392 investors who controlled $\$ 1.35$ trillion of hedge fund assets, including pensions, foundations, endowments, and government organizations, funds of funds, private banks, investment consultants and family offices [20].

Deutsche Bank's tenth annual Alternative Investment Survey conducted in December 2011 by the Bank's Global Prime Finance business predicts increased institutional participation in driving growth as hedge funds become an established and formidable part of the investment landscape. Institutions now account for approximately 
two thirds of hedge funds assets in comparison with less than one fifth in 2003. "Performance continues to be a key, and an increasing number of institutional investors recognize the added benefit hedge funds offer their portfolios" said Anita Nemes, Global Head of Capital Introduction.

Charles Gradante, Co-Founder of Hennessee Group, commented that "Hedge funds are off to the best start since 2000 with improved investor sentiment, greater risk taking, lower correlations and lower volatility. While many risks remain, there is optimism around a better economic outlook for the U.S. and stability in the Euro zone.

Lee Hennessee, Managing Principal of Hennessee Group, said that "Hedge funds performed well in February 2012 generating gains despite conservative exposures. As the investment environment has improved over the last two months, we have seen managers increase exposure levels. Hedge funds are prepared to quickly adjust exposure should conditions dictate, as many feel volatility may rise from currently subdued levels. For example Hennessee Group, LLC, an adviser to hedge fund investors, announced that the Hennessee Hedge Fund Index advanced $+1.72 \%$ in February ( $+4.07 \%$ YTD), while the S\&P 500 advanced $+4.06 \%(+8.60 \%$ YTD $)$, the Dow Jones Industrial Average increased $+2.53 \%(+6.02 \%$ YTD), and the NASDAQ Composite Index climbed $+5.44 \%(+13.89 \%)$ [22].

Kenneth Heinz, President of Hedge Fund Research (HFR), said: "While some have suggested that increased regulation may deter new fund launches, many hedge funds are launching not only as a result of increasing investor risk tolerance, but also as a result of these regulatory changes to trading activities and risk oversight at financial institutions. Despite performance volatility and macroeconomic uncertainty in the second half of 2011, investors maintained a strong commitment to hedge funds, and fund managers expanded the scope and breadth of strategies offered making 2011 the strongest year for new launches since the global financial crisis.

\section{Introduction of regulations}

As discussed earlier, the reason regulations came into effect was largely the result of excessive debt resulting in underpricing and mispricing of risk in the financial crisis of 2008. The observation made in April 2008 by Sebastian Mallaby of the Council on Foreign Relations remains valid even today that hedge fund failures stemmed mainly from errors that were not of their own making. Because banks mismanaged themselves so thoroughly, they had to mobilize capital by calling in loans to hedge funds, forcing the funds to sell off positions precipitously. Forced sales drove down the value of hedge funds' remaining holdings, undermining their creditworthiness and triggered further, calling in of loans, further forced sales, and further losses. This vicious circle caused a few funds to go bust. But the trigger was subprime losses in the regulated banking system [23].

"The criticism was that a highly leveraged hedge fund or group of hedge funds could have had an impact on the prices of the financial markets by launching speculative attacks on certain companies, sectors or currencies. This effect might have reinforced generated herd behavior among investors. They are also accused of manipulating asset prices which contributed to the development of financial bubbles. The decision to prohibit short selling in September 2008 by the authorities in several countries (including the USA and the UK) suddenly changed the regulations governing the market and affected different investment strategies to different degrees creating a negative impact. The ban affected hedge funds because hedge funds use short selling to a greater extent as it makes it more difficult to use strategies that reinforce negative market movements. This made it more difficult to protect long positions through short positions.

Under normal circumstances, hedge funds receive premiums for assuming credit risk, duration risk and liquidity risk that constitute a large part of the hedge funds' profits. During the financial crisis, however, higher risk taking has not led to higher profits for the hedge funds, but rather the opposite that is these entire various premium profits disappeared at the same time. The increased risk premiums could simply not compensate for the losses made by the hedge funds [24].

"The 2008 setback has put the Asian hedge fund industry at risk fighting a tough battle to retain clients as assets shrink and fund closures accelerate making recovery slower in 2011. For example Well known funds such as USD 300 million Thaddeus Capital and morethan-a-decade-old Boyer Allan Investment Management, that once managed USD 1.8 billion, have shuttered as the number of closures surged past launches for the first time since 2008” [25].

"Barriers to entry are the highest ever, the road to closures is steep and slippery, and business sustainability is a key concern," said Dayal, who estimated 67 Asia focused hedge funds closed in 2011 versus 58 launches. Those investing in Asia lost $8.5 \%$ on average, according to Eurekahedge, as largely long biased portfolios failed to absorb market shocks that has led to investors pulling out from funds, resulting in closures and shrinking, many hedge funds to an asset level, which makes it tougher to remain afloat at a time when rising regulatory and compliance burdens are adding to the cost [25].

\section{Regulations and its impact}

Let's dig deeper with regards to the regulations that have been introduced so far around the world. No particular theory has been devised to create these regulations cited below. The industry is driven and trend towards increased regulation of hedge funds and transparency since 2008 helped raise the comfort level of investors with hedge fund managers. This is particularly true of long/short managers who are beginning to draw capital from the investors' long-only allocations. Asia in general does not follow suit with the above.

As of 25 July 2011, hedge fund assets hit the highest in 2011 but generating an alpha return of these assets has proven difficult as there is no particular trend that they can follow because of the unregulated markets. As regulations increase, a trend will be set where they can weigh the pros and cons of the risk existing in the market and make decisions accordingly [26].

Given below are some of the regulations that have been introduced/ going to be introduced after the financial crisis of 2008 :

1) According to Gunther Schneider, Hedge Fund Specialist, Salus Alpha, on the subject of regulation, admits that new laws will "have an impact on all asset managers, but hedge funds/ alternative managers are more in the focus than others". He believes some of the issues being pushed by regulators, like transparency and liquidity, will be good for investors and the market in general. He advocated co-operation with lawmakers and active engagement, rather than sitting on the sidelines as politicians draw up new rules [27].

2) The Financial Services Authority in the UK and other regulators in Europe (Bank for International Settlements and the Financial Stability Forum) have already endorsed the approaches of the Hedge Fund Standards Board in addition to the voluntary 
efforts of the Alternative Investment Management Association (AIMA) and others [9].

3) The G-20 Summit held in London on April 2009, mutually agreed that a regulatory system was needed to identify and evaluate macroeconomic risks. This system would require registration of managers who would disclose necessary information to assess and manage systemic risk and counterparty risk effectively. This action is meant to monitor the leverage and limit the exposure for single counterparty. The Financial Stability Board (FSB) suggested that a common platform be built to share information when hedge funds and fund managers are located in different jurisdictions [28].

4) The SEC in the USA proposed that funds with more than $\$ 150$ million in AUM will have to be registered with the federal agency and turn over a battery of information, including details about their firms, the funds they manage and the types of investors they have. It would also force them to name the businesses that service the funds that are prime brokers, auditors and marketers. Advisers will also have to disclose information that might pose a conflict of interest, like compensation for referrals [29]

This is similar in some context with the hedge fund market in Canada that requires them to be registered in order to manage money for their respective clients. This has proved to be successful in the Canadian market and hence, will be beneficial to the American market as well [30].

5) Recently, speculation has been that hedge funds are being forced to rethink investment strategies as the authorities decide whether to extend short-selling bans. The measures have so far failed to prevent falls in financial stocks, which are heavily exposed to the euro zone debt crisis. The purpose of this was to reduce the market volatility by regulators. Spain has already said it may extend the ban if necessary, while European Securities and Markets Authority chairman Steven Maijoor has said, "we cannot rule out" bans in other countries [31].

6) With the above in mind a new strategy evolved in May 2011 with respect to alpha return named 'Evolved Alpha' that offers solutions that provides transparent, liquid and secure access to a dynamic portfolio of specialized alpha strategies. This portfolio is composed of approximately 1,000 global positions with an emphasis on liquid financial instruments: equities, futures, options and currencies. Evolved Alpha owns all underlying positions, minimizing fraud risk and increasing valuation certainty [32].

7) "The Volcker Rule adopted under the Dodd-Frank Act prohibits banking entities from investing in or sponsoring private equity funds, hedge funds, and venture capital funds, subject to certain exceptions. This rule has been criticized by the financial industry as overly complex and potentially detrimental to the free flow of capital and the growth of the U.S. economy". Chairman Schapiro stated that the implementation of the Volcker Rule "would be a step forward in reducing conflicts of interests between the self-interests of banking entities and the interests of their customers [33].

It also states that "banking entities may own up to 3 percent of a hedge fund that the entity advises and offers to its clients provided that the entity does not subject bank capital to loss by bailing out that fund. These entities may also invest in a hedge fund if the investment is made in connection with effecting a customer transaction. Once implemented in July 2012, fund managers that rely on banking entities as sources of capital should explore other potential sources to continue their business. They should also determine which existing investors are covered as banking entities under the Rule, review operational documents to assess whether withdrawal is permissible for such investors, subscription agreements and compliance programs to ensure that their relationships with existing and future investors comply with the Rule [34].

"The current proposal of the Volcker rule as mandated by the Dodd-Frank Act exempts only trade in U.S. treasuries, without offering the same privilege to debts from other countries, which critics see as a risk to debt markets and banks [35]. Recently, the hedge fund managers reported that Dodd-Frank rules driving increased transparency while increasing investor demand for information have been broadly positive for the industry. Due diligence process, risk management procedures and reporting requirements all have increased investor acceptance of hedge funds, allowing them to become increasingly mainstream investment vehicles for institutional and individual investors [36].

8) According to the article "SEC Tightens Rules on Advisory Performance Fees" posted on $20^{\text {th }}$ February 2012, "the SEC adopted two important grandfather provisions under Rule 205-3 (c) allowing investment advisers to maintain existing performance fee arrangements by raising the standards that apply only to potential "qualified clients" entering new contractual arrangements and not to new investments by existing clients. The new parties to an existing contract would be required to satisfy the requirements in effect at the time they become a party. If a registered investment adviser previously was exempt from registration and did not register, then the restrictions on performance advisory fees under Section 205 (a) (1) will not apply to contractual arrangements the adviser entered into before it became registered. However, the restrictions would still apply to any new investors in the private fund or to the original investors to the extent they invest in a different private fund managed by the adviser. This revised rule also provides that every five years the SEC will issue an order making inflation adjustments to the AUM and net worth dollar thresholds used to determine whether an individual or company is a "qualified client".

9) "In the Netherlands, U.K. and elsewhere in Europe, regulatory pressures on solvency levels are pushing institutional investors to seek hedge fund "In the strategies that target more consistent "bond-like" returns, rather than high-octane alpha, sources said".

10) A hedge fund is a collection of funds because the tax status of investors differs and each fund is designed to optimize taxes for investors. Hence, the tax proposal announced by the Obama administration "includes a provision to shut a loophole under which private equity executives and hedge fund managers pay taxes on their profits at a rate of just $15 \%$, the Huffington Post reports. These profits generally make up the majority of the income of private equity executives and hedge fund managers. Their gains are treated as "carried interest", which is taxed at the $15 \%$ rate. It would instead tax the gains at regular interest rates, which could go up to $35 \%$.

\section{Challenges faced}

Ever since the financial crisis of 2008 occurred, there has been a 
shift in the investor base of hedge fund industry. It is under pressure to adapt to the high expectations and cautious approach characteristic while preserving the investment attributes institutions found appealing in the first place. We will now discuss the key challenges the hedge fund industry faces and what measures should be taken in order to expand the business and investor base successfully. They are as follows:

i. "Demonstrate institutional quality infrastructure and operations: The hedge fund industry size has never been a determinant of success. The survey, conducted by SEI sited that better managed firms produce better returns. Hence, it is unacceptable for funds to handle the administration internally, with half of those feeling a "big name" administrator is required.

ii. Meet investor demand for reporting and transparency: Transparency was the second most commonly named investor worry regarding hedge fund investing. Many prefer portfolio transparency at the sector/industry level while others were concerned with the transparency of the investment process. For many hedge funds, responding to institutional desires for greater transparency and more thorough reporting could entail formidable challenges. One issue is the potential need for upgraded or redesigned infrastructure to enable delivery of sufficiently detailed data. Even thornier problems crop up when hedge funds are invested in instruments that are so illiquid, complex, or unusual that no ready source of objective valuation exists. Many types of bonds and derivatives are traded privately, making valuations in the absence of fresh transaction data highly subjective. Changing markets may also make assets such as mortgage-backed securities and leveraged loans difficult to value.

iii. Build a stable management team with a full range of skill sets: hedge funds require a complex range of skill sets and dedicated staffing of key positions in order to be well managed and achieve long term success. Recruitment and retention were much less prominent on the list of concerns for prominent on the list of concerns for hedge fund managers. The prospect of more freedom and richer rewards had talented investment professionals flocking to the hedge fund industry. More recently, however, the rapid proliferation and asset growth of hedge funds markedly intensified the competition for talent. Amusingly, some of the keenest competition now is for experienced non-investment professionals.

iv. Shift focus from performance to investment disciplines: Institutional investors tend to invest with a different rationale than high-net-worth investors. Rather than high absolute returns, they seek stable returns and exposure to non-correlated strategies. Track record requirements can be problematic, given that nearly two-thirds of hedge funds were established within the last five years. Limits on the scalability of hedge fund strategies are another strong concern. These concerns can be addressed by:

a. Framing their capabilities in terms of investment disciplines rather than strictly performance delivery.

b. "Sticking to their knitting" as they build their clientele. Institutions will want to know what growing funds are doing to preserve their winning attributes, especially where boutique managers are concerned.

c. Funds employing strategies vulnerable to overcrowding may wish to consider applying their strategy to a wider range of asset classes or geographies. The advantages of expansion will of course need to be weighed against the demands for additional research, trading, and infrastructure capacity.

v. Keep abreast of public policy and regulatory trends: The issue of hedge fund regulation remains very much in play. The industry continues to address a range of public policy issues with a recent focus on proposed tax policy changes and tightening accounting standards. Institutional investors will continue to take the steps needed to ensure that their hedge fund manager meets the highest possible standards for their compliance and general business practices. One needs to keep up with a changing regulatory environment for smooth functioning" [37].

vi. "Entrepreneurial innovation being reduced: While there have been multiple launches over the last year, the size of the launches has become smaller. It will be a challenge to find service providers and partners that want to make an investment in resources to facilitate all of the data feeds that are now required. It is not insurmountable, but it will be harder for investment managers to start out" [38].

vii. "Danger of increasing cost: Increasing data flow obligations and taking on additional liability and functions is going to add significantly to the costs of the investment manager that will accelerate in an environment where returns have been inconsistent [38]

\section{Summary}

As reviewed in this chapter, the author has discussed how hedge funds function, the role played by alpha, and the regulations introduced/planning to be introduced to regulate the hedge fund market. The literature also discusses in detail the challenges hedge fund market faces and what needs to be done for its smooth functioning. After a review of Chapter 2, there appears to be no formal study or theory that links to the development of these regulations. It is done as per what the SEC feels is best overall in the market. The main reason regulations came into play has been already discussed above that is the financial crisis of 2008 and setback caused.

The theory is still lacking research within the former areas when attempting to explain the role and impact of regulations and alpha in the hedge fund industry. The literature review can only suggest that the regulations developed are according to the circumstances of the situation (that is a crisis) and demand of the market to avoid losses and setbacks to the individual investors and companies as well.

The following section on research methodology will further examine the methods used for gathering the qualitative and quantitative data and the formulas used. We will also discuss the pros and cons of these methods, collection and analysis of data.

\section{Research Methodology}

\section{Overview}

The research methodology is both qualitative and quantitative using an exploratory research approach to identify the main aspects and influences of regulations on the hedge fund industry. This study aims to build a framework to further investigate the current trends emerging in the study of new regulations coming up and the impact it has on alpha component; as well as study the main consequences of 
these if the market remains unregulated. The analysis is derived from an extensive literature review covering the unregulated industry, the financial crisis of 2008, introduction of regulations and its impact on the worldwide market so far.

\section{Appriopriateness}

The present study, has selected a qualitative research methodology to understand what various hedge fund specialists feel about regulations being introduced and its impact on the overall market. Qualitative research allows for developing a deeper understanding of existing problems within the phenomenon and allows the author to formulate and converge new ideas with old. Qualitative research is eminent for investigating complex and sensitive issues. Qualitative research allows for analysis of how people think and generates in-depth information about specific topics.

An open-ended questionnaire permits a wide array of possible responses to the research question and allows the participants to free associate prior to data analysis. Furthermore, the questionnaire methodology is most advantageous as the author cannot know all the possible questions within this understudied domain. Moreover, such a study should avoid the possibility of suggesting answers to the participants or responder. In summary, this survey method was selected in order to ensure that respondents answer in their own voice.

Quantitative analysis evaluates how alpha return has increased/ decreased after regulations. However, there are chances that not enough data is accumulated to generate alpha and show its impact otherwise. Miscalculations could also cause discrepancy in results.

\section{Research design}

The research paradigm and methodology used will be phenomenological by the way of exploratory research using mixed methods (that is qualitative and quantitative). 'Exploratory Research' is conducted 'to obtain greater understanding of a concept by identifying essential variables that need to be studied [39].

It is an ideal technique for doing extensive research studies and since, the topic on regulations of hedge funds is an ongoing research area in the present and coming future, it blends in perfectly.

"Firstly, exploratory research can assist researchers in finding possible causes to the symptoms communicated by decision makers (that is forming regulations).

Secondly, exploratory research can uncover possible avenues for reaching decision makers' objectives (that is reasons behind forming regulations).

Thirdly, exploratory research answers questions about actually administering a large and expensive research project (that is impact of regulations on hedge funds and alpha in future)".

The qualitative method used to conduct this study will involve the administration of questionnaires (open format) using the professional networking site linkedin.com (via web based surveys using surveymonkey.com). The population (approximately 24) attempting this survey will be experienced professionals belonging to the hedge fund industry around the world. The questionnaires will be designed to ask the specific questions with respect to the research topic and will not take more than 20 minutes to complete. This gathered data will be analyzed to conclude to the possible outcomes.

Also, data gathered with regards to alpha from various hedge fund databases will be assessed to see the end result if any significant changes have occurred. Hypothetically, dummy data was gathered (approximately 51) of portfolio return and market return from various indices and generate alpha and beta using Excel and presented it graphically. Data from Barclays Hedge Fund database is used to relate alpha with regulations.

Using Excel, alpha=Portfolio return mean - monthly risk free rate - beta $^{*}$ (market return - risk free rate) that is CAPM model that is Expected Return=Risk-Free Rate + Beta $^{*}$ (Expected Return of the Market - Risk-Free Rate).

Using Excel, beta=covariance of portfolio return and market return/variance of portfolio return and market return.

Beta $<0$ : Negative Beta - not likely.

Beta $=0$ : Cash in the bank.

Beta Between 0 and 1: Low-volatility

Beta $=1$ : Matching the market.

Beta > 1: More volatile than the market.

To calculate whether a hedge fund manager added alpha based on the risk taken, simply substitute the beta of the hedge fund into CAPM model, which would result in an expected return on the hedge fund's performance. If the actual returns exceed the expected return, the hedge fund manager added alpha based on the risk taken else vice versa, even though the actual returns might have been higher than the relevant benchmark.

The formula for calculating alpha using the arithmetic method is:

$[(\operatorname{sum}$ of $y)-((b)(\operatorname{sum}$ of $x))] / n$, where:

$\mathrm{n}=$ number of observations (36 mos.);

$\mathrm{b}=$ beta of the fund;

$\mathrm{x}=$ rate of return for the market; and

$y=$ rate of return for the fund.

"But the problem with simple arithmetic is that it always produces the wrong answer. Alpha is either inflated (when the market is up) or deflated (when the market is down) by the percentage change in the benchmark itself" [40].

The other method of generating alpha would be using regression statistical method for analysis on the returns of the funds to be studied.

$\mathrm{R}$ (fund) $=\mathrm{alpha}+\mathrm{beta}^{*} \mathrm{R}$ (indices), where the returns are computed by subtracting the riskless rate of return.

\section{Validity and reliability}

The proposed study is bounded by several limitations mentioned below. That is, the advantages of administering questionnaires are as follows:

i. "Web page surveys are extremely fast. A questionnaire posted on a Website can gather several thousand responses in a short period of time. No cost is involved once the setup has been completed.

ii. Web page questionnaires can use colors, fonts, and other formatting options that is not possible in most email surveys.

iii. People will give long answers to open-ended questions on Web page questionnaires". 
The potential disadvantages are stated as follows:

i. "People can easily quit in the middle of a questionnaire. They are not as likely to complete a long questionnaire on the Web as they would be if talking with a good interviewer. If the survey pops up on a web page, one has no control over who replies, that is anyone cruising that web page may answer.

ii. There is often no control over people responding multiple times to bias the results.

iii. Business-to-business research and employee attitude surveys can often meet this requirement.

Be sure the survey software prevents people from completing more than one questionnaire by restricting access via password [41].

The possible limitations while carrying out this study could be that data gathered using surveys may be not sufficient enough to deduce any solid conclusions with respect to the research question. The data gathered could be attempted multiple times by the same person causing redundancy within the data. Others could be that the statistical method used to analyze alpha wasn't interpreted properly and more variables were needed for better analysis. As the hedge fund is still a relatively unexplored area with respect to the other areas of finance, lack of information and experience in the respective industry could also cause miscalculations resulting in possible failure of the results of the research.

The other problems that can occur while assessing the returns of hedge funds are: the past performance of a particular hedge fund may give a very selective view of its risk, a fair estimate of hedge fund returns will need to adjust performance for market exposure, and calculating hedge fund returns involves problems of valuation.

To ensure validity and reliability of data accumulated, triangulation method is used. Since the study consists of mixed components (both qualitative and quantitative data), triangulation becomes a necessity to validate through cross verification from other sources via methodological triangulation (within methods) as stated above by checking with newspaper articles, working papers, books and published work of my fellow colleagues and academic professionals and scholars.

The information provided by the hedge fund specialists via questionnaires and conclusions will be deduced by analyzing the data gathered from various indices of hedge funds to see the fluctuations in the alpha and how regulations have created an impact in the industry.

\section{Data collection}

The survey method collected data by direct participation of the people working within the hedge fund industry around the globe via www.linkedin.com. Each participant received the survey by email and had no time constraints (Appendix). Each person participated in the survey by filling out the questionnaire posted on www.surveymonkey. com. The data tabulated from the small sample provided a more relevant information and subsequent knowledge.

Let's suppose that alpha is calculated using Excel with hypothetical portfolio returns and market returns respectively. This will give an idea of what alpha and beta will be. Scenario of 2012 will be presented with indices and their respective alphas. This might help to study the pattern, whether the alpha has improved or declined over the years. Hopefully, the conclusion will indicate whether regulations affect alpha or not.

\section{Data analysis}

The six-item questionnaire was designed to gather information with regards to regulating the hedge fund industry, the challenges faced, its importance and how imposing regulations will affect the alpha. Content analysis was the approach to quantifying the responses within the questionnaire, in order to make the study systematic and replicable. The important issues and special content provided within the survey were proofread by the researcher. If there existed any discrepancies between the transcribed texts, then it would not be considered. Graphs were then developed with associated content by analyzing the questionnaire segments along with the interview segments. Over a twomonth period more than two hundred questionnaires were distributed and twenty 24 were returned via linkedin.com and emails, resulting in a response rate of $12 \%$.

The quantitative method uses the first dataset from various hedge fund indices with their respective alpha components before 2008 and after 2008. The hypothetical scenario using dummy dataset mentioned above will help us generate and present alpha using Excel. The data presented will give us a slight idea if any major changes occurred in the value of alpha over the period of time and how one generates alpha. The third dataset collected from Barclay's Hedge Fund Database will involve funds only based in the USA for the purpose of evaluating alpha. However, we cannot ignore the fact that performance in the market as well can impact alpha and hence, deducing the value of alpha would be slightly difficult to interpret.

\section{Summary}

The study employed an original six-item questionnaire consisting of title in the industry with open-ended questions. The qualitative methodology utilized in this study allowed collecting the opinions of the hedge fund specialists on the creation of regulations, challenges they think the industry will face, the impact on alpha and their suggestions regarding what type of regulations be created. The responses were then analyzed, and categorized in order to develop a further understating of the opinions and understandings of various people belonging to the hedge fund industry.

The quantitative methodology uses hypothetical portfolio return and market values to generate alpha using Excel with graphical presentation. The data gathered from indices with respective alphas over a period will show us the pattern of the market and thus we can relate if regulations create an impact on alpha. The subsequent chapter will delve in to more extensive detail.

\section{Presentation of the Data}

\section{Purpose statement}

As previously mentioned, the purpose of this study is to understand the purpose of creating regulations, its impact on the hedge fund industry, the challenges faced in the industry and the effect it has on alpha factor before and after the financial crisis that is whether regulations proved to be beneficial or hazardous.

\section{Research method}

The methodology used within this study is exploratory research using mixed methods (that is qualitative and quantitative). The qualitative method used to conduct this research will involve the administration of questionnaires (open format, primary data) while the quantitative method uses various hedge fund indices (secondary data) to calculate alpha and study the pattern of alpha before and after 2008 . 
Citation: Chadha P (2016) Impact of Regulations on Hedge Funds and the Potential Impact on Alpha in 2012. Int J Account Res S1: 009. doi: 10.4172/2472-114X.S1-009

\section{Data collection}

The survey method was utilized for studying the opinion/ viewpoints of various professionals presently working in the hedge fund industry. Data collected via survey questionnaires was sent by email. Completed surveys were ultimately received within two months. Only 24 respondents replied to the survey out of 300 people who were contacted via email for their participation.

The quantitative method uses 51 dummy values of portfolio return and market value to generate alpha and beta, which will be represented graphically. The other secondary data will represent various indices with their respective alphas graphically to show the movement in the current market scenario. The third dataset from Barclay's Hedge Fund database will help us evaluate alpha better in correspondence to the regulations. Although there are no guaranteed results of the methodology used below.

\section{Data distillation}

The results provide some perspective on the findings of some recent work. This section will provide a detailed explanation of the resulting information collected from the previously stated instrument and method used in this study. The 24 participant responses allowed the researcher to transcribe the collected information in the form of pie chart: The people that participated have the following job titles in the hedge fund industry. They range from an analyst level to the top management level (Figure 1).

The majority participants suggested that regulations are required while the rest of them stated that the regulations could be used to some extent/not required at all (Figure 2).

Rules and regulations are required in any industry for its proper structure, smooth functioning and maintenance. Here, the importance of regulations in the hedge fund industry is stated below (Figure 3).

The challenges that exist in the market in terms of regulating hedge funds are characterized below: The major challenges are with respect to hedging strategies and increasing transparency and disclosure. About $1 / 4^{\text {th }}$ population thinks that no challenges exist. While the rest of the population believes that challenges exist when limit is put on withdrawals, not willing to join regulated bodies and fragmented market everywhere (Figure 4).

The effect of regulations on alpha return cannot be judged theoretically, but needs quantitative work as well which will be

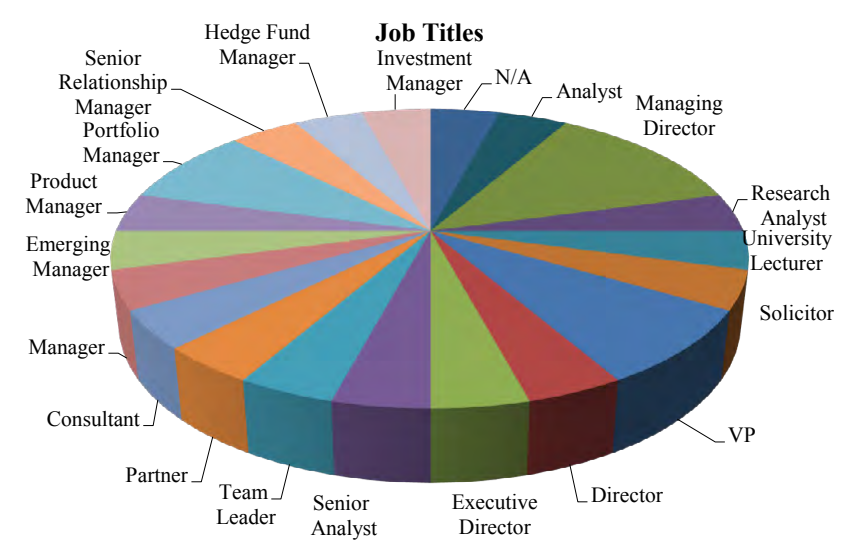

Figure 1: Job titles of participants.

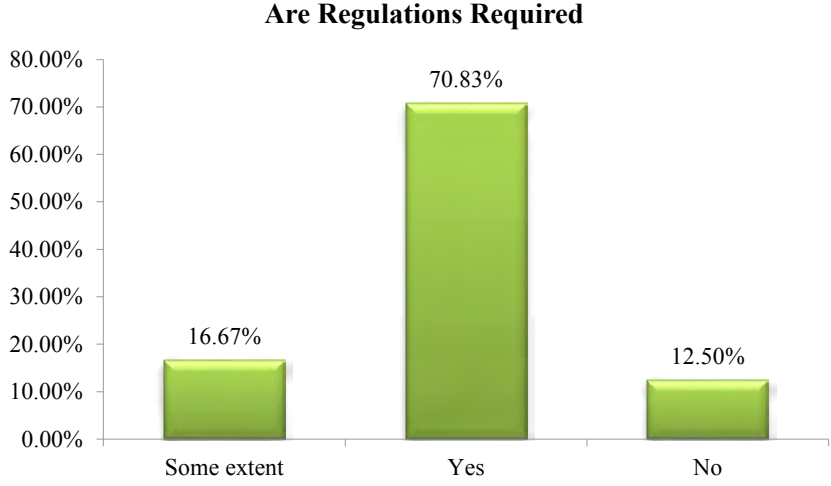

Figure 2: Are regulations required in the current scenario.

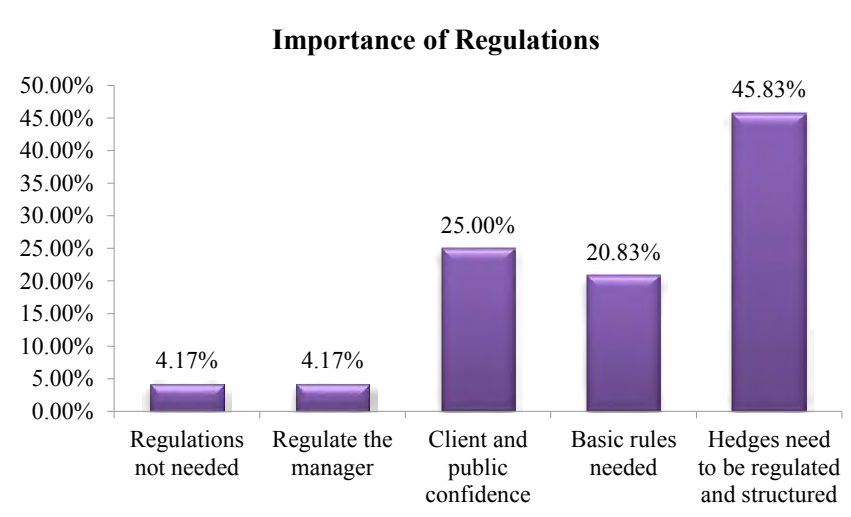

Figure 3: Importance of regulations in the hedge fund industry.

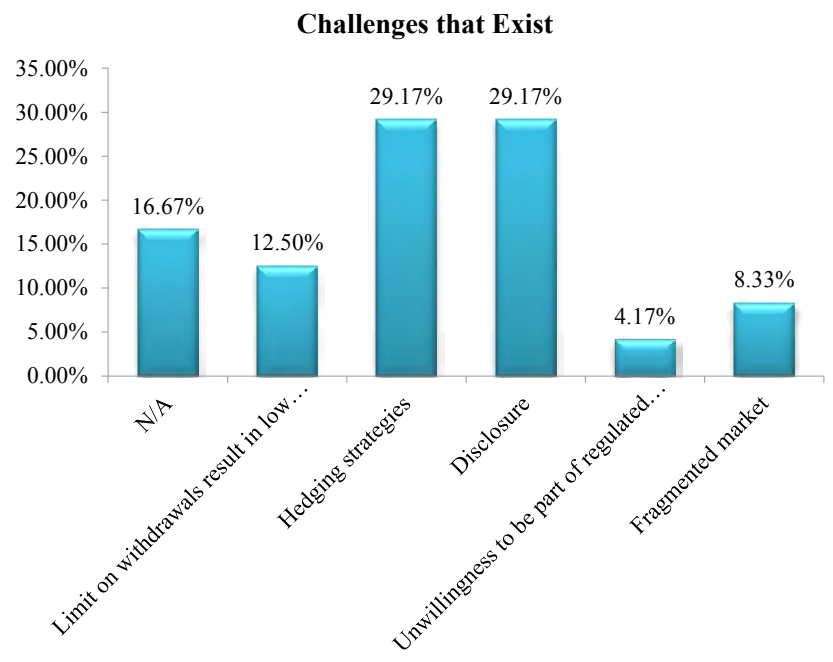

Figure 4: Challenges that exist in the market currently.

presented later. These were the responses received when asked about alpha return: $33.33 \%$ suggested that regulations will not have an effect on alpha while $25 \%$ suggested that it is irrelevant and not related. The others responded with different opinions such as the positive and negative effect on alpha, increase and decrease alpha, normalize or limit alpha (Figure 5). 
Citation: Chadha P (2016) Impact of Regulations on Hedge Funds and the Potential Impact on Alpha in 2012. Int J Account Res S1: 009. doi: 10.4172/2472-114X.S1-009

Page 11 of 17

Lastly, enquiry was conducted to see if any new policies are needed in order to improve the hedge fund industry and these are the following responses: $33.33 \%$ suggested that no new policies are applicable and market needs to remain unregulated while $20.83 \%$ insisted that there should increase transparency with regards to information in the industry. They also suggested that new processes be developed to manage risk, leverage and other factors. Others suggested that a standardized system be developed worldwide with strict regulations and leverage in the industry. They also suggested that the forbiddance of short selling be stopped (ban on short selling due to financial crisis of 2008) (Figure 6).

The dummy dataset of portfolio return and market return used to generate alpha and beta is derived from various managers of different hedge funds. The range varies from positive $0 \%$ to negative $54 \%$ portfolio return, whereas market return ranges from $0 \%$ to negative $42 \%$. We have also calculated the excess profit/loss generated from this data sample (Table 1).

The next secondary data set is taken from the Dow Jones Credit Suisse Core Hedge Fund Index, which includes hypothetical and actual performance from December 31, 2005 to February 29, 2012, showing their annualized returns (Table 2).

The third data set (approximately 50) is collected from a Barclays Hedge Fund database to identify and relate the alpha returns with the regulations that exist in the industry. This data consists of only Managers in NY, NJ, CT and MA (USA) and ranges from different portfolio content such as equity, fixed income, fund of funds, macro, merger arbitrage, multi strategy, mutual fund/ETF, option strategies and regulation D/PIPEs (Table 3 ).

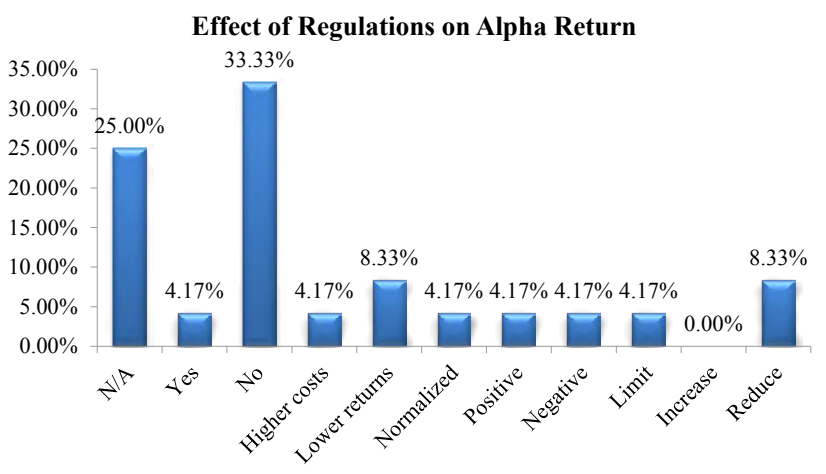

Figure 5: Effect of regulations on alpha return.

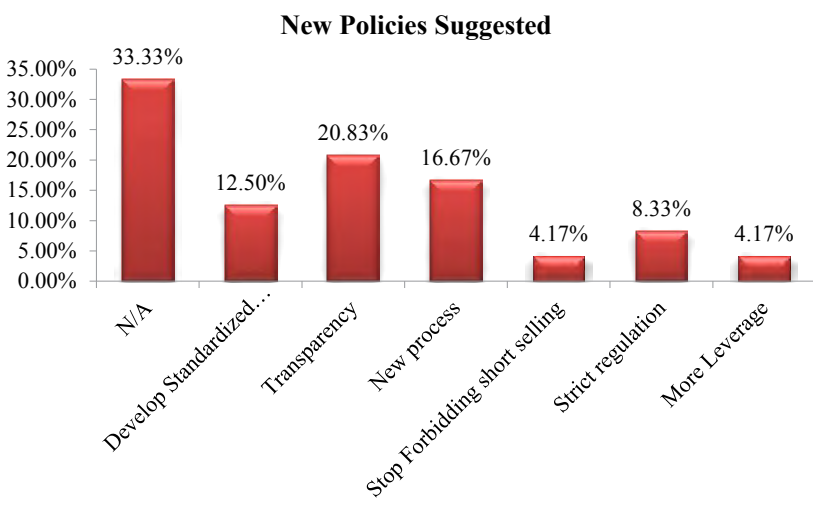

Figure 6: New policies needed to improve the hedge fund industry.

\begin{tabular}{|c|c|c|c|}
\hline \multirow[t]{2}{*}{ Serial No. } & \multicolumn{3}{|c|}{ Returns } \\
\hline & Portfolio & Market & Excess \\
\hline 1 & $7.39 \%$ & $7.06 \%$ & $0.33 \%$ \\
\hline 2 & $5.79 \%$ & $5.16 \%$ & $0.63 \%$ \\
\hline 3 & $5.63 \%$ & $3.42 \%$ & $2.21 \%$ \\
\hline 4 & $8.26 \%$ & $10.24 \%$ & $-1.98 \%$ \\
\hline 5 & $1.87 \%$ & $-5.00 \%$ & $6.87 \%$ \\
\hline 6 & $22.03 \%$ & $14.00 \%$ & $8.03 \%$ \\
\hline 7 & $40.48 \%$ & $-42.00 \%$ & $82.48 \%$ \\
\hline 8 & $29.14 \%$ & $33.00 \%$ & $-3.86 \%$ \\
\hline 9 & $-8.52 \%$ & $11.00 \%$ & $19.52 \%$ \\
\hline 10 & $74.91 \%$ & $80.00 \%$ & $-5.09 \%$ \\
\hline 11 & $50.22 \%$ & $57.00 \%$ & $-6.78 \%$ \\
\hline 12 & $47.60 \%$ & $42.00 \%$ & $5.60 \%$ \\
\hline 13 & $41.44 \%$ & $50.36 \%$ & $-8.92 \%$ \\
\hline 14 & $6.94 \%$ & $6.65 \%$ & $0.29 \%$ \\
\hline 15 & $6.35 \%$ & $4.35 \%$ & $2.00 \%$ \\
\hline 16 & $9.15 \%$ & $1.38 \%$ & $7.77 \%$ \\
\hline 17 & $7.58 \%$ & $4.77 \%$ & $2.81 \%$ \\
\hline 18 & $-20.93 \%$ & $23.73 \%$ & $-44.66 \%$ \\
\hline 19 & $0.42 \%$ & $8.57 \%$ & $-8.15 \%$ \\
\hline 20 & $52.07 \%$ & $49.06 \%$ & $3.01 \%$ \\
\hline 21 & $0.67 \%$ & $2.84 \%$ & $-2.17 \%$ \\
\hline 22 & $79.94 \%$ & $64.05 \%$ & $15.89 \%$ \\
\hline 23 & $70.32 \%$ & $86.15 \%$ & $-15.83 \%$ \\
\hline 24 & $70.25 \%$ & $81.70 \%$ & $-11.45 \%$ \\
\hline 25 & $62.10 \%$ & $52.38 \%$ & $9.72 \%$ \\
\hline 26 & $6.94 \%$ & $-10.10 \%$ & $17.04 \%$ \\
\hline 27 & $6.35 \%$ & $-9.90 \%$ & $16.25 \%$ \\
\hline 28 & $9.15 \%$ & $-9.91 \%$ & $19.06 \%$ \\
\hline 29 & $2.53 \%$ & $-2.49 \%$ & $5.02 \%$ \\
\hline 30 & $-2.62 \%$ & $0.11 \%$ & $-2.73 \%$ \\
\hline 31 & $-2.31 \%$ & $-4.55 \%$ & $2.24 \%$ \\
\hline 32 & $1.13 \%$ & $-4.33 \%$ & $5.46 \%$ \\
\hline 33 & $1.89 \%$ & $-2.67 \%$ & $4.56 \%$ \\
\hline 34 & $1.51 \%$ & $-2.69 \%$ & $4.20 \%$ \\
\hline 35 & $1.51 \%$ & $2.01 \%$ & $-0.50 \%$ \\
\hline 36 & $-20.93 \%$ & $-13.79 \%$ & $-7.14 \%$ \\
\hline 37 & $18.83 \%$ & $-11.84 \%$ & $30.67 \%$ \\
\hline 38 & $-16.98 \%$ & $-10.91 \%$ & $-6.07 \%$ \\
\hline 39 & $-19.77 \%$ & $-26.44 \%$ & $6.67 \%$ \\
\hline 40 & $-4.80 \%$ & $17.70 \%$ & $-22.50 \%$ \\
\hline 41 & $-22.39 \%$ & $-27.06 \%$ & $4.67 \%$ \\
\hline 42 & $-6.42 \%$ & $8.37 \%$ & $-14.79 \%$ \\
\hline 43 & $-5.36 \%$ & $-5.70 \%$ & $0.34 \%$ \\
\hline 44 & $50.64 \%$ & $79.17 \%$ & $-28.53 \%$ \\
\hline 45 & $67.39 \%$ & $79.17 \%$ & $-11.78 \%$ \\
\hline 46 & $49.09 \%$ & $47.44 \%$ & $1.65 \%$ \\
\hline 47 & $64.96 \%$ & $54.35 \%$ & $10.61 \%$ \\
\hline 48 & $-20.36 \%$ & $24.31 \%$ & $-44.67 \%$ \\
\hline 49 & $31.80 \%$ & $-33.28 \%$ & $65.08 \%$ \\
\hline 50 & $-53.65 \%$ & $54.35 \%$ & $-108.00 \%$ \\
\hline 51 & $91.43 \%$ & $90.67 \%$ & $0.76 \%$ \\
\hline Mean & $17.87 \%$ & $18.54 \%$ & $-0.67 \%$ \\
\hline
\end{tabular}

Table 1: Data set collected.

\section{Summary}

The responses from various participants were presented via pie charts with respect to the questions asked in the survey. These responses were categorized into the respective job titles and their answers with respect to the other questions in the survey. The hypothetical 
Citation: Chadha P (2016) Impact of Regulations on Hedge Funds and the Potential Impact on Alpha in 2012. Int J Account Res S1: 009. doi: 10.4172/2472-114X.S1-009

Page 12 of 17

\begin{tabular}{|c|c|c|c|c|c|c|c|}
\hline Indices & 2006 & 2007 & 2008 & 2009 & 2010 & 2011 & 2012 \\
\hline DJCS Core Hedge Fund Index & $12.4 \%$ & $20.1 \%$ & $-6 \%$ & $13.1 \%$ & $8.1 \%$ & $-7.4 \%$ & $3.6 \%$ \\
\hline DJCS Core Convertible Arbitrage Hedge Fund Index & $13.2 \%$ & $1.2 \%$ & $-30.3 \%$ & $46.2 \%$ & $11.2 \%$ & $-7.7 \%$ & $5.9 \%$ \\
\hline DJCS Core Emerging Markets Hedge Fund Index & $23.3 \%$ & $34.1 \%$ & $-23.9 \%$ & $26.9 \%$ & $9.9 \%$ & $-2.4 \%$ & $3.7 \%$ \\
\hline DJCS Core Event Driven Hedge Fund Index & $13 \%$ & $21.3 \%$ & $-16.6 \%$ & $20.8 \%$ & $7.2 \%$ & $-12.5 \%$ & $4.4 \%$ \\
\hline DJCS Core Fixed Income Arbitrage Hedge Fund Index & $10.6 \%$ & $16.4 \%$ & $11.5 \%$ & $3.3 \%$ & $4.5 \%$ & $-1.3 \%$ & $1.4 \%$ \\
\hline DJCS Core Global Macro Hedge Fund Index & $4.6 \%$ & $15.2 \%$ & $12 \%$ & $5.8 \%$ & $8.3 \%$ & $-10.1 \%$ & $2.9 \%$ \\
\hline DJCS Core Long/Short Equity Hedge Fund Index & $12.7 \%$ & $19.4 \%$ & $-10.3 \%$ & $19.1 \%$ & $6.8 \%$ & $-7.3 \%$ & $5.3 \%$ \\
\hline DJCS Core Managed Futures Hedge Fund Index & $12 \%$ & $16.8 \%$ & $30.1 \%$ & $-12.6 \%$ & $13.8 \%$ & $-3 \%$ & $1.7 \%$ \\
\hline
\end{tabular}

Table 2: Hypothetical and actual annual performance.

\begin{tabular}{|c|c|c|c|c|c|c|}
\hline S. No. & Name & Min. Account(\$) & Total Return & Max. Drawdown & YTD Return & 1 Yr. Return \\
\hline 1 & 400 Capital Credit Opportunities Fund L.P. & $5000 \mathrm{~K}$ & $74.78 \%$ & $2.91 \%$ & $6.90 \%$ & $6.62 \%$ \\
\hline 2 & Abundance Partners, L.P. & $500 \mathrm{~K}$ & $1148.10 \%$ & $21.62 \%$ & $-4.80 \%$ & $1.11 \%$ \\
\hline 3 & Apprecia Capital Fund I L.P. & $250 \mathrm{~K}$ & $135.40 \%$ & $72.90 \%$ & $20.90 \%$ & $-10.67 \%$ \\
\hline 4 & AQR DELTA Full Volatility Fund (Master) & $5000 \mathrm{~K}$ & $48.25 \%$ & $3.43 \%$ & $0.10 \%$ & $1.44 \%$ \\
\hline 5 & Azimuth Diversified Fund, LLC & $1000 \mathrm{~K}$ & $24.84 \%$ & $18.45 \%$ & $2.50 \%$ & $-2.97 \%$ \\
\hline 6 & Balestra Capital Partners, L.P. & $2000 \mathrm{~K}$ & $1615.12 \%$ & $36.24 \%$ & $0.10 \%$ & $7.80 \%$ \\
\hline 7 & Bodleian Partners A, L.P. & $1000 \mathrm{~K}$ & $371.14 \%$ & $24.42 \%$ & $4.40 \%$ & $-3.16 \%$ \\
\hline 8 & Boston Company Long/Short Opportunistic Equity Fund LP & $1000 \mathrm{~K}$ & $72.93 \%$ & $21.87 \%$ & $12.40 \%$ & $2.25 \%$ \\
\hline 9 & CastleRock Partners, L.P. & $1000 \mathrm{~K}$ & $1068.01 \%$ & $39.42 \%$ & $6.40 \%$ & $-19.48 \%$ \\
\hline 10 & Catalpa Allocator Portfolio & $100 \mathrm{~K}$ & $3.88 \%$ & $0 \%$ & $3.80 \%$ & $0 \%$ \\
\hline 11 & CSat Market Neutral & $500 \mathrm{~K}$ & $58.81 \%$ & $4.77 \%$ & $4.80 \%$ & $12.32 \%$ \\
\hline 12 & CURA Fixed Income Arbitrage Master Fund & $1000 \mathrm{~K}$ & $54.18 \%$ & $16.28 \%$ & $-0.70 \%$ & $0.50 \%$ \\
\hline 13 & EACM Absolute Return Fund, Ltd & $1000 \mathrm{~K}$ & $44.49 \%$ & $18.61 \%$ & $4.20 \%$ & $0.05 \%$ \\
\hline 14 & Eagle Stone Partners, LP & $250 \mathrm{~K}$ & $6.36 \%$ & $7.60 \%$ & $7.80 \%$ & $0 \%$ \\
\hline 15 & Ferrell Concert Ltd. & $500 \mathrm{~K}$ & $41.72 \%$ & $49.50 \%$ & $1.60 \%$ & $-6.89 \%$ \\
\hline 16 & Firebird Global Fund, L.P. & $100 \mathrm{~K}$ & $389.57 \%$ & $50.06 \%$ & $8.20 \%$ & $-29.06 \%$ \\
\hline 17 & Goldman Sachs Hedge Fund Opportunities, Ltd. & $1000 \mathrm{~K}$ & $35.72 \%$ & $15.26 \%$ & $3.60 \%$ & $1.15 \%$ \\
\hline 18 & Goldstein Capital Managed Bond Portfolio & $500 \mathrm{~K}$ & $272.74 \%$ & $22.23 \%$ & $0.90 \%$ & $4 \%$ \\
\hline 19 & Hagin Cash Plus Market Neutral & $250 \mathrm{~K}$ & $0.19 \%$ & $3.41 \%$ & $0 \%$ & $1.17 \%$ \\
\hline 20 & Haidar Jupiter Fund, LLC & $100 \mathrm{~K}$ & $404.06 \%$ & $16.92 \%$ & $-2.90 \%$ & $46.79 \%$ \\
\hline 21 & Invitational Opportunity Fund LLC & $500 \mathrm{~K}$ & $75.48 \%$ & $19.56 \%$ & $5.80 \%$ & $-5.40 \%$ \\
\hline 22 & Island Drive Partners L.P. & $1000 \mathrm{~K}$ & $-51.36 \%$ & $71.45 \%$ & $9.10 \%$ & $6.14 \%$ \\
\hline 23 & J.P. Morgan Multi-Strategy Fund Ltd - Series CA (USD) & $5000 \mathrm{~K}$ & $21.80 \%$ & $18.91 \%$ & $4 \%$ & $0.23 \%$ \\
\hline 24 & Juniper Public Fund, L.P. & $1000 \mathrm{~K}$ & $31.11 \%$ & $18.45 \%$ & $11.90 \%$ & $8.22 \%$ \\
\hline 25 & Kalo Capital Management, LP & $500 \mathrm{~K}$ & $3.67 \%$ & $11.92 \%$ & $8.20 \%$ & $-3.81 \%$ \\
\hline 26 & Kane Street Fund LP & $500 \mathrm{~K}$ & $31.84 \%$ & $14.05 \%$ & $12.70 \%$ & $9.09 \%$ \\
\hline 27 & Lazard Alternative Strategies Fund LLC & $500 \mathrm{~K}$ & $63.50 \%$ & $12.65 \%$ & $2.30 \%$ & $-3.04 \%$ \\
\hline 28 & Leveraged High-Yield Fund & $500 \mathrm{~K}$ & $89.40 \%$ & $13.43 \%$ & $16.30 \%$ & $22.98 \%$ \\
\hline 29 & M.D. Sass Multi-Strategy Partners II, L.P. & $1000 \mathrm{~K}$ & $296.80 \%$ & $25.27 \%$ & $3.70 \%$ & $-3.84 \%$ \\
\hline 30 & Magister Ludi Global Macro Fund L.P. & $200 \mathrm{~K}$ & $-10.12 \%$ & $47.02 \%$ & $24 \%$ & $-18.13 \%$ \\
\hline 31 & Nantahala Capital Partners, L.P. & $1000 \mathrm{~K}$ & $199.89 \%$ & $7.22 \%$ & $6.60 \%$ & $1.47 \%$ \\
\hline 32 & Navesink River Partners, L.P. & $250 \mathrm{~K}$ & $173.18 \%$ & $43.39 \%$ & $8.50 \%$ & $4.01 \%$ \\
\hline 33 & Ocean Partners, LLC & $500 \mathrm{~K}$ & $560.19 \%$ & $33.71 \%$ & $6.90 \%$ & $3.29 \%$ \\
\hline 34 & Old Kings Capital, L.P. & $1000 \mathrm{~K}$ & $121.74 \%$ & $22.94 \%$ & $8.40 \%$ & $1.29 \%$ \\
\hline 35 & Pan Multi Strategy L.P. & $100 \mathrm{~K}$ & $646.06 \%$ & $24.66 \%$ & $4.50 \%$ & $-4.41 \%$ \\
\hline 36 & Peconic Grenadier Fund & $1000 \mathrm{~K}$ & $1296.75 \%$ & $46.52 \%$ & $-0.20 \%$ & $-23.06 \%$ \\
\hline 37 & Quantum Strategic Value Fund & $1000 \mathrm{~K}$ & $79.82 \%$ & $8.93 \%$ & $12 \%$ & $17.09 \%$ \\
\hline 38 & Ramius Alternative Replication Fund Ltd. & $5 \mathrm{~K}$ & $0.19 \%$ & $8.06 \%$ & $2.10 \%$ & $-2.22 \%$ \\
\hline 39 & Saguenay Offshore Fund, Ltd. Class A & $1000 \mathrm{~K}$ & $58.43 \%$ & $16.61 \%$ & $2.10 \%$ & $-4.16 \%$ \\
\hline 40 & Sancus Capital Select Partners Offshore & $500 \mathrm{~K}$ & $16.44 \%$ & $6.99 \%$ & $0.70 \%$ & $-5.59 \%$ \\
\hline 41 & T Squared Investments LLC & $500 \mathrm{~K}$ & $582 \%$ & $57.63 \%$ & $7.20 \%$ & $-40.73 \%$ \\
\hline 42 & TAG Diversified Strategies Fund, LP & $1000 \mathrm{~K}$ & $12.33 \%$ & $17.11 \%$ & $3.20 \%$ & $-2.39 \%$ \\
\hline 43 & UCM Opportunistic Mortgage Strategy Fund & $5000 \mathrm{~K}$ & $46.38 \%$ & $5.36 \%$ & $4.10 \%$ & $-0.58 \%$ \\
\hline 44 & van Biema Asia Value Fund, LP & $1000 \mathrm{~K}$ & $50.64 \%$ & $17.86 \%$ & $11.60 \%$ & $-3.22 \%$ \\
\hline 45 & W Financial Fund, L.P. Class B & $1000 \mathrm{~K}$ & $129.60 \%$ & $0 \%$ & $1.20 \%$ & $12.20 \%$ \\
\hline 46 & Walbert Diversified Strategy Fund, L.P. & $250 \mathrm{~K}$ & $57.79 \%$ & $17.21 \%$ & $3 \%$ & $-0.22 \%$ \\
\hline 47 & YA Global Investments II, Ltd. (Class A) & $1000 \mathrm{~K}$ & $159.54 \%$ & $0.53 \%$ & $1.70 \%$ & $18.08 \%$ \\
\hline 48 & Yankee Multi-Manager Fund L.P. & $500 \mathrm{~K}$ & $314.82 \%$ & $29.83 \%$ & $0.40 \%$ & $-2.81 \%$ \\
\hline 49 & Zanett Opportunity Fund, Ltd. & $500 \mathrm{~K}$ & $-34.78 \%$ & $59.26 \%$ & $-2.20 \%$ & $-41.11 \%$ \\
\hline 50 & Zebra Global Liquidity Arbitrage Fund LP & $1000 \mathrm{~K}$ & $14.08 \%$ & $2.06 \%$ & $-1.10 \%$ & $4.63 \%$ \\
\hline
\end{tabular}

Table 3: Data set collected from barclay hedge fund database. 
quantitative data gathered using different indices is presented via tables and graphical images. This chapter showed the opinions/views of various participants that develop further understanding of the research question and, hopefully, we can derive to a concrete conclusion using both the qualitative and quantitative data. The subsequent chapter will go into more extensive detail on the synthesis and integration of the research findings.

\section{Synthesis and Integration}

\section{Overview}

The present study was conducted using professional networking site www.linkedin.com (via web based surveys using www.surveymonkey. com) using twenty four hedge fund professionals within the field of hedge fund industry. The survey method was used to collect and generate a set of responses with respect to the issues regarding regulations.

The first dummy quantitative dataset was collected using various indices to generate alpha and beta using Excel. The second data set was used to show the findings of the years prior and after 2008 in order to study the trend of alpha. The subsequent section will synthesize and integrate the nature of these findings. The third data set from Barclay Hedge Fund database will show us more extensively the analyses of alpha, monthly average returns, beta, sharpe ratio and standard deviation that will help us to relate the impact of regulations more clearly.

\section{Analysis of findings}

The findings have been discussed partially with respect to the qualitative research conducted using the survey method mentioned in the earlier chapter. The analysis of this method is as follows:

* Participants from different hierarchical levels have attempted this survey when asked about their respective job titles.

* When asked if regulations are required in the current scenario after the financial crisis of 2008, the majority supported the fact that regulations were very much needed to prevent losses to the investor by suggesting an increase in transparency and managing risk. While, minority don't agree with the idea of regulations in the hedge fund industry.

* When enquired about the importance of regulations in the hedge fund industry, the findings were that an authority/ agency can oversee the proper functioning of the industry using global standardization of operations. With regulations in place, speculations can be controlled. It will ensure that no single fund or group of funds poses a systemic risk to the U.S. and global financial markets by increasing transparency, reducing market abuse, market manipulation, operational risks, investment risk, and limiting excessive risk taking by managers. The most critical point is that client and public confidence be maintained.

* The challenges that presently exist in the market are: failure/ loss of hedge funds will occur if limit is put on withdrawals due to regulations, lack of transparency and clarity, complex financial instruments and hedging strategies, unwillingness to be a part of and be regulated by certain international bodies like Financial Stability Board, same regulations around the globe in order to avoid regulatory arbitrage, disclosure by managers, and overall cost will limit smaller funds ability to compete. The current unregulated state of the industry gives the hedge fund managers room to attempt high risk strategies (short selling, complex derivatives) which, when regulated might be curbed leading to a reduction in their flexibility. This may lead to hedge fund operations resembling mutual fund operations, in terms of restrictions and regulations. The hedge fund industry might lose investors who invest in these funds due to their ability to take on higher risk and thereby generate higher returns.

* Majority suggested that the regulations will not affect alpha return as it is not related, but others suggested that alpha return will definitely reduce due to a reduction in the fund manager's propensity to take on risk. They also mentioned that regulations will lead to higher costs, which will be passed on to investors, leading to lower returns by limit investment opportunities and increase costs of execution.

* Finally, the new policies suggested by the participants were: to develop a standardized system that will enable hedge funds to electronically in an easy and effective way without requiring them to disclose proprietary trading strategies and positions, stop forbidding all sorts of short selling by allowing to sell a security that has been borrowed before the sale, and continue to forbid the sale of a security that is neither owned nor borrowed, enable leverage in UCITS funds, and allow commodities, because right now it is allowed anyways through TR Swaps, which are just expensive and brings banks in the middle without which, alpha would go up and punish severely for stock manipulation, insider trading, shorting deals, etc. Minority also suggested that hedge fund industry should remain unregulated.

Let's discuss and analyze the findings of the quantitative method that was used to generate alpha and beta respectively, using hypothetical sample (approx.51) of portfolio return and market return from various indices. And, have a look into the other indices used for alpha before and after 2008.

Table 1 in previous chapter shows the sample data collected for portfolio return and market return. The formula used to calculate alpha and beta have been previously discussed in Chapter 3 . The formulas are as follows:

In Excel, alpha=Portfolio return mean - monthly risk free rate - beta $^{*}$ (market return - risk free rate) that is CAPM model that is Expected Return=Risk-Free Rate + Beta $^{*}$ (Expected Return of the Market - Risk-Free Rate) (Figure 7).

In Excel, beta=covariance of portfolio return and market return/ variance of portfolio return and market return.

Monthly risk free rate $=0.25 \%$ (assumed)

The end result is stated below:

\begin{tabular}{c|c} 
Beta & 0.66836 \\
\hline Alpha & $5.39 \%$ \\
\hline
\end{tabular}

The Beta of 0.66836 signifies that Beta Between 0 and 1: Lowvolatility results in higher alpha that is $5.39 \%$. This means that market is less volatile that makes it safe for investors to invest resulting in higher profit generation for hedge fund managers' that is alpha return. However, the sample data used here to only show how alpha is calculated and doesn't correlate with the regulations. 


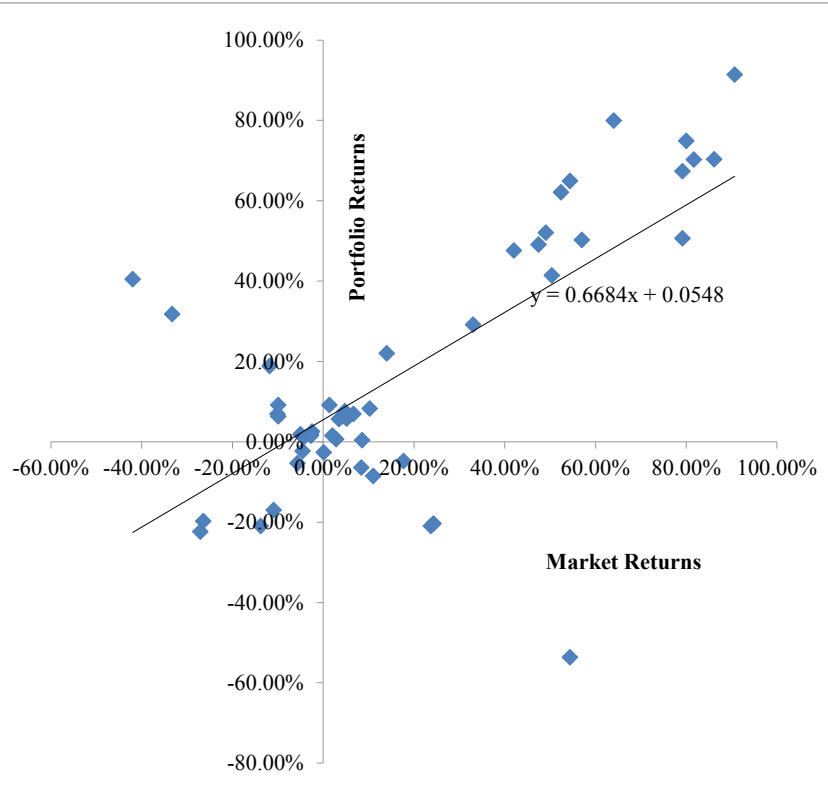

Figure 7: Graphical representation.

The next data set (Table 2) is taken from the Dow Jones Credit Suisse Core Hedge Fund Index that includes hypothetical and actual performance from December 31, 2005 to February 29, 2012, showing their yearly annualized returns prior to 2008 and after 2008 (Here the annualized returns are alphas of the respective indices).

Prior to 2008, the returns were quite high and positive, indicating that unregulated market was performing well and generating excessive profits. Due to the financial crisis in 2008, most of the indices were generating negative returns.

After 2008, the hedge funds seemed to generate positive returns, but could not match the benchmark set prior to 2008 with slight losses in the Futures Hedge Fund Index. The regulations formed since then for example a unified regulatory system, registration of funds equal and greater than $\$ 150$ million AUM, ban on certain investment strategies like short selling,(previously mentioned in Chapter 2) helped improve the market to a certain extent. The year 2011 saw negative returns due to Asian crises indicating that the regulations are very much required in order to stable the hedge fund market.

With new regulations being implemented in 2012 like Volker Rule under Dodd Frank Act, tightening of advisory performance fees, the passport system in Europe, the tax proposal to close the loop holes, (previously mentioned in Chapter 2), we can see that Q1 of 2012 has generated positive returns, making it possible for smaller hedge funds to perform well. The returns as we can see in the graphical representation below are no match when in comparison with 2006, but it creates a positive hope that regulating the hedge fund industry will generate positive alpha and any change in the market directly and indirectly reflects the alpha depending upon the investment strategy used (Figure 8).

Finally, the last data set will show us two different periods of analyses that is prior to 2008 and after 2008. These diagnostics will show us how the presence and non-presence of regulations might have impacted the performance of the hedge fund industry (Tables 4 and 5).

In this actual scenario, the comparison shows that the incentive fee has increased after 2008 with a slight drop in the annual returns. Also, the alpha has significantly dropped with simultaneous increase in beta showing the variations in the market.

\section{Summary}

This chapter can be summarized by stating that the survey method was used to generate the opinions/views of the various hedge fund specialists with regards to regulations and its impact. After a comprehensive analysis of the research findings, the results have revealed that there are 50-50 who support regulations and who don't favor regulations. The quantitative method used shows how alpha and beta is calculated using Excel by using a dummy sample data set. The second sample data used from various indices shows us the pattern of alpha returns from December 2005 to February 2012. The final dataset from Barclay Hedge Fund actually showed us the comparative market analysis helped us to correlate the impact of regulations on alpha return depending upon the respective investment portfolios. The following chapter will review and explore the conclusive nature of the findings to provide recommendations for future research.

\section{Conclusions and Recommendations}

\section{Concluding thoughts}

Hedge funds seem to be popular in spite of the worst performances since the financial crisis because it carries an expression of status, prestige, exclusivity, and sophistication, according to Larry Swedroe, CBS News. Growth and innovation in the hedge fund industry has directed significant attention to a sector of the financial industry that enjoys unmatched flexibility. The hedge fund industry is changing from an industry that exercised substantial control over its sources of funds into an industry that must accommodate investor demands regarding fund operations in order to compete for investment growth. The

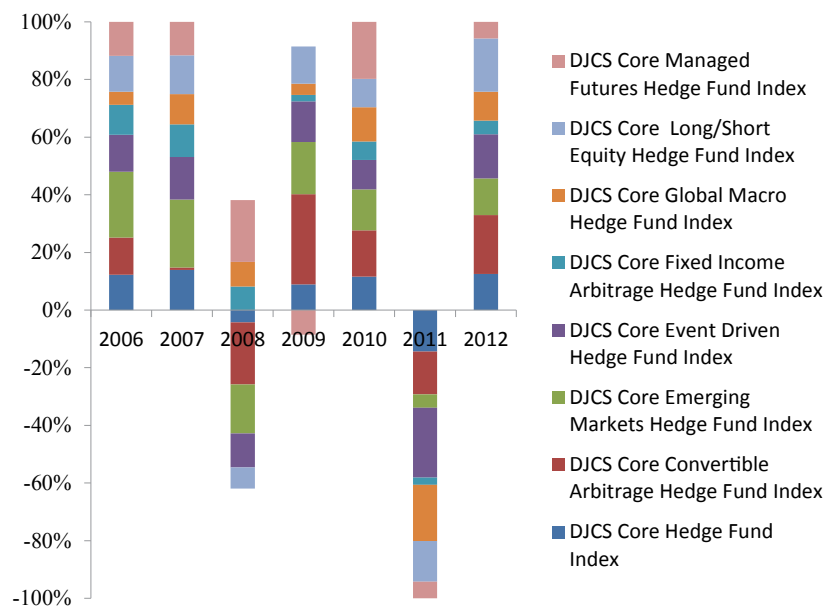

Figure 8: Graphical representation.

\begin{tabular}{|l|c|}
\hline Avg. Mgmt. Fee & $1 \%$ \\
\hline Avg. Incentive Fee & $13 \%$ \\
\hline Avg. Compund Annual Return & $10.73 \%$ \\
\hline Avg. Monthly SD & 4.16 \\
\hline Avg. Sharpe Ratio & 0.82 \\
\hline Avg. Alpha vs S\&P500 & 0.81 \\
\hline Avg. Beta vs S\&P500 & 0.28 \\
\hline Avg. R2 vs S\&P 500 & 0.27 \\
\hline
\end{tabular}

Table 4: Barclay hedge fund data prior and up to 2008. 
Citation: Chadha P (2016) Impact of Regulations on Hedge Funds and the Potential Impact on Alpha in 2012. Int J Account Res S1: 009. doi: 10.4172/2472-114X.S1-009

Page 15 of 17

\begin{tabular}{|c|c|c|c|c|c|c|c|c|c|}
\hline Name & Start Date & Mgmt Fee & Incentive Fee & $\begin{array}{l}\text { Compound } \\
\text { Annual Return }\end{array}$ & $\begin{array}{l}\text { Monthly Standard } \\
\text { Deviation }\end{array}$ & Sharpe Ratio & $\begin{array}{l}\text { Alpha vs } \\
\text { S\&P500 }\end{array}$ & $\begin{array}{c}\text { Beta vs S\&P } \\
500\end{array}$ & $\begin{array}{l}\text { R2 vs } \\
\text { S\&P500 }\end{array}$ \\
\hline $\begin{array}{l}400 \text { Capital Credit Opportunities } \\
\text { Fund L.P. }\end{array}$ & 9-Feb & $2 \%$ & $15 \%$ & $19.85 \%$ & 2.02 & 2.82 & 1.36 & 0.11 & 0.08 \\
\hline $\begin{array}{l}\text { YA Global Investments II, Ltd. } \\
\text { (Class A) }\end{array}$ & 9-Apr & $1.50 \%$ & $20 \%$ & $37.72 \%$ & 2.83 & 3.84 & 2.34 & 0.21 & 0.12 \\
\hline van Biema Asia Value Fund, LP & 9-Jun & $1 \%$ & $20 \%$ & $15.55 \%$ & 4.5 & 0.99 & 0.16 & 0.75 & 0.56 \\
\hline $\begin{array}{l}\text { Sancus Capital Select Partners } \\
\text { Offshore }\end{array}$ & 9-Aug & $2 \%$ & $20 \%$ & $5.87 \%$ & 1.48 & 1.13 & 0.34 & 0.1 & 0.1 \\
\hline $\begin{array}{l}\text { UCM Opportunistic Mortgage } \\
\text { Strategy Fund }\end{array}$ & 9-Aug & $0.75 \%$ & $10 \%$ & $15.35 \%$ & 1.88 & 2.34 & 1.04 & 0.13 & 0.09 \\
\hline Hagin Cash Plus Market Neutral & 9-Sep & $0.30 \%$ & $20 \%$ & $0.07 \%$ & 0.76 & -0.01 & 0.01 & 0 & 0 \\
\hline Kane Street Fund LP & 9-Sep & $1.50 \%$ & $15 \%$ & $11.68 \%$ & 3.56 & 0.94 & 0.16 & 0.66 & 0.73 \\
\hline $\begin{array}{l}\text { Magister Ludi Global Macro Fund } \\
\text { L.P. }\end{array}$ & 9-Sep & $2 \%$ & $20 \%$ & $-4.17 \%$ & 11.55 & -0.11 & -2.11 & 1.95 & 0.61 \\
\hline $\begin{array}{l}\text { Ramius Alternative Replication } \\
\text { Fund Ltd. }\end{array}$ & 9-Oct & $1 \%$ & $0 \%$ & $0.08 \%$ & 1.45 & -0.01 & -0.31 & 0.28 & 0.83 \\
\hline Juniper Public Fund, L.P. & 10-Mar & $1.50 \%$ & $20 \%$ & $13.88 \%$ & 5.2 & 0.77 & 0.14 & 0.86 & 0.64 \\
\hline $\begin{array}{l}\text { Zebra Global Liquidity Arbitrage } \\
\text { Fund LP }\end{array}$ & 10-Jun & $1.50 \%$ & $20 \%$ & $7.44 \%$ & $1.17 \%$ & 0.02 & 0.61 & 0 & 0 \\
\hline Kalo Capital Management, LP & 10-Oct & $2 \%$ & $20 \%$ & $2.42 \%$ & 2.35 & 0.29 & -0.44 & 0.47 & 0.67 \\
\hline Eagle Stone Partners, LP & 11-May & $2 \%$ & $20 \%$ & $6.95 \%$ & 2.59 & 0.77 & 0.36 & 0.4 & 0.54 \\
\hline Catalpa Allocator Portfolio & 12-Jan & $0.75 \%$ & $0 \%$ & $16.45 \%$ & 1.38 & 3.43 & -6.09 & 1.83 & 0.49 \\
\hline \multicolumn{6}{|l|}{ Avg. Mgmt. Fee } & \multicolumn{4}{|c|}{$1 \%$} \\
\hline \multicolumn{6}{|l|}{ Avg. Incentive Fee } & \multicolumn{4}{|c|}{$16 \%$} \\
\hline \multicolumn{6}{|l|}{ Avg. Compund Annual Return } & \multicolumn{4}{|c|}{$10.65 \%$} \\
\hline \multicolumn{6}{|l|}{ Avg. Monthly SD } & \multicolumn{4}{|c|}{2.97} \\
\hline \multicolumn{6}{|l|}{ Avg. Sharpe Ratio } & \multicolumn{4}{|c|}{1.23} \\
\hline \multicolumn{6}{|l|}{ Avg. Alpha vs S\&P500 } & \multicolumn{4}{|c|}{-0.17} \\
\hline \multicolumn{6}{|l|}{ Avg. Beta vs S\&P500 } & \multicolumn{4}{|c|}{0.55} \\
\hline \multicolumn{6}{|l|}{ Avg. R2 vs S\&P 500} & \multicolumn{4}{|c|}{0.39} \\
\hline
\end{tabular}

Table 5: Barclay hedge fund data after 2008.

challenge to regulators is to construct a framework that accommodates fund management flexibility while offering investors appropriate manager monitoring tools.

The growth in institutional investment in hedge funds offers an approach to regulation that balances both management flexibility and generates monitoring externalities that would likely benefit all types' hedge fund investors [42].

Large firms, in particular, seemed to welcome the additional scrutiny, with large majorities favoring SEC registration, the European Passport and a majority backing supervision from the Treasury and the Federal Reserve Bank.

Kenneth J Heinz, president of HFR, said, "While some have suggested that increased regulation may deter new fund launches, many hedge funds are launching not only as a result of increasing investor risk tolerance, but also as a result of these regulatory changes to trading.

Activities and risk oversight at financial institutions. The hedge fund industry has and will continue to expand and innovate to offer more sophisticated and transparent strategies to meet the requirements of institutional investors [43].

This chapter is dedicated to the summarization of the results presented in the previous chapter, as well as the conclusions that can be derived from the gathered data. This study is focused on the critical evaluation of the role played by regulations in the hedge fund industry. This dissertation discusses how hedge funds were created and its salient features, how they function, the reasons that regulations were created, the challenges faced in the hedge fund industry, and the recent events with regards to regulations currently. The research also aimed to identify what alpha stands for and the impact of regulations on alpha.

Primary and secondary resources were used in the study. For the primary data, the researcher opted to conduct a survey using hedge fund specialists as participants from www.linkedin.com. An open ended questionnaire, structured in www.surveymonkey.com, was used for data gathering. The answers of the respondents were then processed by analyzing via percentage of support each response got. The results of these were then presented via charts. Secondary resources derived from various hedge fund indices websites were integrated to support the respective findings. These findings include a sample of how alpha and beta are calculated using Excel, various indices data set to understand the impact before 2008 and after and finally a further market analysis using actual data set from Barclay Hedge Fund database [44-47].

Based from the results of the survey, the open ended questionnaires play an important role in understanding the opinion/view points of the various participants with regards to regulations. Each respondent has his/her own unique belief. The study conducted has yielded some conclusions based on the findings that were summarized in the previous chapter. It is now possible to derive several conclusions based on the objectives presented in the first chapter. These conclusions are the following:

* The huge losses that incurred to investors and other financial institutions in 2008 crisis led to the creation of regulations to prevent such damages in the near future.

* Although many were opposed to the idea of regulating an unregulated market, officials and regulators thought that it is in 
the best interest for the industry to have regulations introduced to keep track of the transactions by introducing hedge fund registration system, illegal frauds, and profit making by the hedge fund managers.

* The new regulations that are in the process of being implemented will only bring out the best in the system, for example, Hedge Fund Market in Canada and Latin America hasn't faced any troubles during the crisis as they operate under regulations [48]. Although many believe that these regulations are created only for the benefit of the regulators and serve no interest to the common investor.

* Suggestions by majority participants were that there be more transparency and disclosure to the investors by the hedge fund managers with regards to the transactions and movements in the market.

* A global regulatory body should also be created for monitoring the function of hedge funds universally. SEC and FSB in USA are keeping tabs at the moment.

* "Managers expect their operational cost will rise due to increased costs of the regulations found in the Dodd-Frank bill".

* The challenges the industry faces with respect to the regulations have been discussed in the previous sections. But regulators are working on solving each of these one at a time. However, oppositions will be present everywhere whenever solutions are recommended.

* Majority also commented that creation of regulations will not affect alpha at all. But any market movement or control in investment strategies will create a positive or negative impact on alpha that can be seen in the findings from the earlier chapter.

The validity and accuracy of the results obtained from these questionnaires are continuously questioned. Considering that applicants can easily fake their responses, the results would naturally be affected. Moreover, while this tool is relatively inexpensive, one needs to ensure correct analysis and interpretation of the results. Misinterpretation of literatures is still very likely; hence, it is difficult to employ a strategy whose outcome is not guaranteed. The data gathered for calculation purposes can also be inaccurate; hence, the results generated will not be error free. Market conditions are ignored here.

Hence, creation of regulations will affect the investment strategies that in turn will affect alpha overall indirectly. But, cannot determine yet the effect of the upcoming regulations on alpha yet.

The hedge fund industry risks, challenges it poses, investment strategies, returns it generates and its implications as a whole are yet to be understood. This is an area that still requires lots of exploration and research to fully comply with what hedge fund specialists' do, why they do and how regulators introduce solutions for the proper functioning of this industry. Through this paper, best was done to present a very tiny aspect of this industry by answering all the positive questions we raised in the beginning.

Douglas Cumming says, "there is an ambiguous relation between hedge fund regulation and hedge fund structure and performance. On one hand, a lack of regulatory oversight may give rise to fund managers that disguise investment schemes and merely capture the fees. Hedge fund registration and oversight would curb this type of behavior and thereby improve hedge fund structure and average performance [49].
On the other hand, regulatory oversight may hamper fund performance where hedge fund managers and their investors lose freedom to contract and organize their resources in the way that they deem to be most efficient, and thereby exacerbate agency problems". The lower alphas, standard deviations and returns indicate that regulations do impact the performance of hedge funds by lowering the risks that exist in the market.

Let's conclude that regulations have a positive impact on the industry and alpha "as they are the "shock absorbers" in the marketplace, by investing in volatile markets when other investors choose to remain on the sidelines [50]. They also add depth and liquidity to all areas of the capital markets, which contributes to efficiencies in pricing and promotes market stability. Finally, hedge funds often act as effective risk transfer conduits in the capital markets, particularly in the area of corporate and high yield credits. These regulations will only help in future to eradicate the possible risks, errors and frauds that occur in the industry.

\section{References}

1. Gabelli MJ (2000) The History of Hedge Funds - The Millionaire's Club.

2. Investopedia (2009) Quantitative Analysis of Hedge Funds.

3. Hedge Funds (2000) In Search of Alpha. The Basics Revisited

4. http://eprints.Ise.ac.uk/24675/1/dp477.pdf

5. Geithner TF (2004) Hedge Funds and Their Implications for the Financial System. Federal Reserve Bank of New York.

6. Chriss NA (1998) Introduction to Hedge Funds.

7. http://asaha.com/ebook/zMjQ5NTc2/Post-Crisis-Hedge-Funds,-CustodialRisk-and-Prime-Brokers.pdf

8. http://lawvibe.com/the-debate-over-regulation-of-hedge-funds/

9. Ziff B (2008) Partner of Oliver Wyman's Corporate Investment Banking practice. Financial Services - Point of View Series: 4 Round, Two: Challenges for Hedge Funds in the financial crisis.

10. Kaal W, Oesterle D (2016) The History of Hedge Fund Regulation in the United States. The CLS BLU SKY BLOG.

11. Weiss G (2006) Wall Street versus America: The Rampant Greed and Dishonesty That Imperil Your Investments. NY Times.

12. Swann C (2009) Do Android Hedge Funds Dream of Alpha? Reuters Breaking views.

13. Stulz RM (2007) Hedge Funds: Past, Present, and Future. The Journal of Economic Perspectives. American Economic Association 21: 175-194.

14. Oranika P. Should Hedge Funds Be Regulated? Hedge Co.

15. Felix (2006) Hedge funds, alpha, and beta.

16. Hedge Fund (2007) Alpha Hedge Fund.

17. Gongloff M (2011) Hedge Funds Kiss Their Alpha Goodbye. Wall Street Journal.

18. Hedge Co (2012) The Dodd Frank Bill Views From The Hedge Fund Industry.

19. Pfeuti E (2012) Bumper Hedge Fund Launches as Performance Converges. Aicio.

20. Hua T (2012) European Institutional Investors to Lean more on Hedge Funds Allocation increases tied to concerns over Funding, Volatility. Pensions \& Investments.

21. Akesson A (2012) Deutsche Bank Hedge Fund Survey Predicts Growth And Increased Institutional Participation.

22. Hedge Co (2012) Eurekahedge Launches New Insurance Linked Hedge Fund Index.

23. Hedge Fund Facts. Hedge Funds. How They Serve Investors in the U.S. and Global Markets.

24. Stromqvist M (2009) Hedge Funds and the Financial Crisis of 2008. Economic Commentaries. pp: 1-5. 
Citation: Chadha P (2016) Impact of Regulations on Hedge Funds and the Potential Impact on Alpha in 2012. Int J Account Res S1: 009. doi: 10.4172/2472-114X.S1-009

25. Reuters (2012) Closures, Losses Push Back Asia Hedge Fund Industry. Money Control.

26. Williamson $C$ (2011) Alpha hard to come by for hedge fund managers in first half of 2011. Pensions \& Investments.

27. Lindsay M (2011) Video: Interview with Günther Schneider, hedge fund specialist. Salus Alpha - Hedge Funds Review.

28. Noh H (2009) Hedge Funds in the Post-crisis Era: Discussion on Global Regulations and Korea's Plan. Korea Capital Market Institute 1: 39-55.

29. Ahmed A (2010) SECReadies Hedge Fund Rules. DealBook -NY Times.

30. McGovern J, Ostoich G (2005) Hedge Fund Industry in Canada. AIMA.

31. Fletcher $L$ (2011) Hedge funds brace for more short-selling bans. REUTERS (US).

32. Hedge Fund Lounge (2011) Evolved Alpha Opens Flagship Hedge Fund to New Investors.

33. Hedge Co (2012) Hedge Funds Off To Best Start In Over A Decade.

34. Investment Law (2012) SEC Tightens Rules on Advisory Performance Fees.

35. Darragh R (2012) G20 Hopeful U.S. Will Revise Volcker Rule. The Compliance Exchange.

36. Hedge Co (2012) New Evidence Reveals Goldman Sachs Engaged In Secret Re-titling Into Goldman's Name Alone Of Over 20 Million Shares Owned By Marvell Founders.

37. SEIC (2007) Five Critical Challenges for Hedge Funds. Taking Aim at the Institutional Market. SEI Knowledge Partnership Insights for Investment Managers.
38. Hedge Funds Review (2012) BNY Mellon: Challenges and Opportunities Emanate from Regulation.

39. McKenzie K, Danforth S (2009) Problem Definition, Exploratory Research, and the Research Process, Wiley.

40. Ehrbar A (2009) How do you Calculate Alpha? 2008 Market Crash Lays Bare Flaw in Conventional Alpha Measuring. Pensions \& Investments.

41. Creative Research Systems. Survey system.

42. Westbrook H (2003) Hedge Fund Industry Structure and Regulatory Alternatives.

43. Seeking Alpha (2012) Over 1,000 Hedge Funds Launched In 2011.

44. Cumming D (2008) Don't Fence them in, Hedge Fund Regulation and Performance. pp: 26-33.

45. Denscombe M (2007) The Good Research Guide for Small-Scale Social Research Projects. (3rd edn), McGraw Hill Open University Press. pp: 134-136.

46. Devasabai K (2010) Hedge Funds Face Challenges of 2011 with Optimism Facing the Future. Hedge Funds Review.

47. Hu, Bei (2012) Hedge Fund Assets May Rise to Record, Deutsche Bank Survey, Business Week.

48. Mallaby S (2008) Blame the Banks. Foreign Affairs.

49. Reingold D (2006) Confessions of a Wall Street Analyst: A True Story of Inside Information and Corruption in the Stock Market. Publishers Weekly.

50. Swedroe L (2012) Despite their rep, hedge funds disappoint. CBS News. 